\title{
Let's face emotions!
}

Citation for published version (APA):

Alabak, M. (2022). Let's face emotions! Towards a more comprehensive understanding of emotional labor strategies. [Doctoral Thesis, Maastricht University]. Maastricht University.

https://doi.org/10.26481/dis.20220120ma

Document status and date:

Published: 01/01/2022

DOI:

10.26481/dis.20220120ma

Document Version:

Publisher's PDF, also known as Version of record

\section{Please check the document version of this publication:}

- A submitted manuscript is the version of the article upon submission and before peer-review. There can be important differences between the submitted version and the official published version of record.

People interested in the research are advised to contact the author for the final version of the publication, or visit the DOI to the publisher's website.

- The final author version and the galley proof are versions of the publication after peer review.

- The final published version features the final layout of the paper including the volume, issue and page numbers.

Link to publication

\footnotetext{
General rights rights.

- You may freely distribute the URL identifying the publication in the public portal. please follow below link for the End User Agreement:

www.umlib.nl/taverne-license

Take down policy

If you believe that this document breaches copyright please contact us at:

repository@maastrichtuniversity.nl

providing details and we will investigate your claim.
}

Copyright and moral rights for the publications made accessible in the public portal are retained by the authors and/or other copyright owners and it is a condition of accessing publications that users recognise and abide by the legal requirements associated with these

- Users may download and print one copy of any publication from the public portal for the purpose of private study or research.

- You may not further distribute the material or use it for any profit-making activity or commercial gain

If the publication is distributed under the terms of Article $25 \mathrm{fa}$ of the Dutch Copyright Act, indicated by the "Taverne" license above, 


\section{LET'S FACE EMOTIONS!}

Towards a more comprehensive understanding of emotional labor strategies

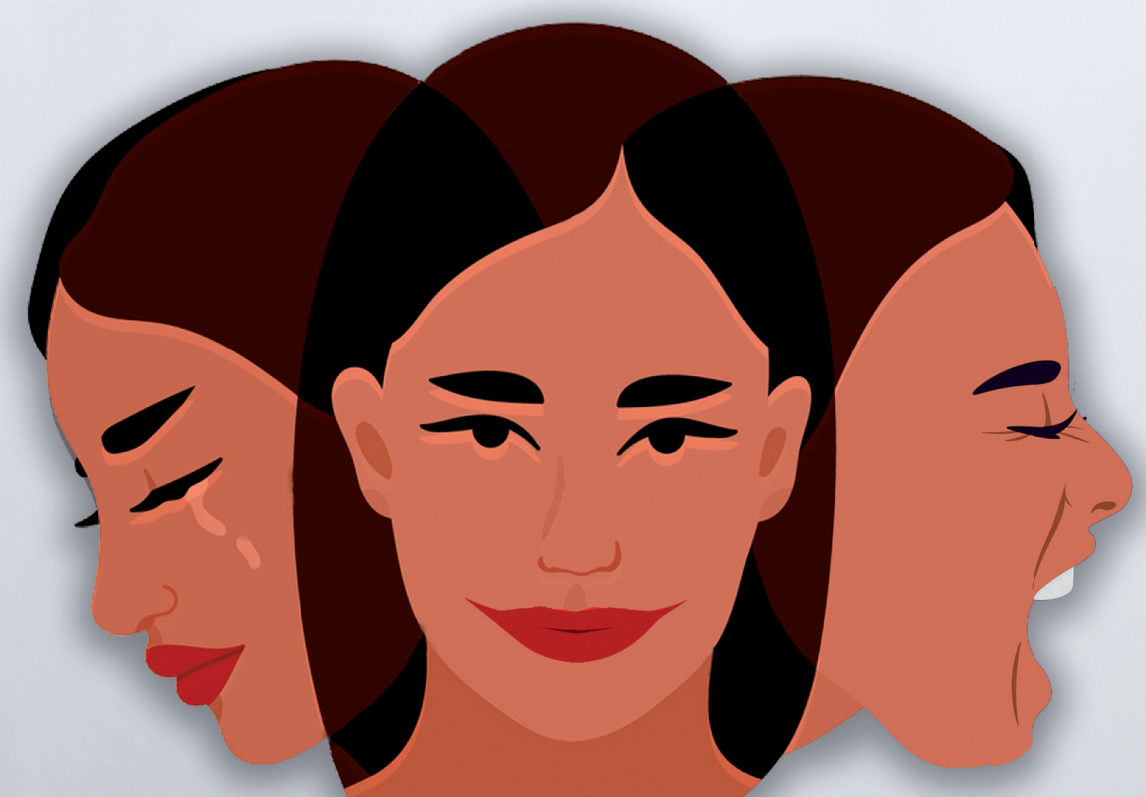

Merve Alabak 
Let's face emotions!

Towards a more comprehensive understanding of emotional labor strategies

Merve Alabak 
ISBN 978-90-832173-0-7

Cover design: Mustafa Kart

Print: Printservice Ede

(C) Merve Alabak 2021

All rights are reserved. No part of this book may be reproduced, distributed, stored in a retrieval system, or transmitted in any form or by any means, without prior written permission of the author. 


\title{
Let's face emotions!
}

\section{Towards a more comprehensive understanding of emotional labor strategies}

\author{
DISSERTATION \\ To obtain the degree of Doctor at Maastricht University, \\ On the authority of the Rector Magnificus, \\ Prof. Dr. Rianne M. Letschert \\ In accordance with the decision of the Board of Deans, \\ To be defended in public \\ On January 20, 2022
}

by

Merve Alabak 


\section{Supervisors}

Prof. Dr. U.R. Hülsheger

Prof. Dr. Fred R. H. Zijlstra

\section{Co-supervisor}

Dr. Philippe Verduyn

\section{Assessment Committee}

Prof. Dr. Rob A. C. Ruiter (chair)

Prof. Dr. Joeri Hofmans (Vrije Universiteit Brussel)

Prof. Dr. Simon de Jong

Associate Prof. Dr. Sjir G.J.A.M.L. Uitdewilligen

Prof. Dr. Hans de Witte (University of Leuven) 


\section{Table of contents}

Chapter 1 General introduction

Chapter 2 A review of emotional labor research: The road behind and the road ahead

Chapter 3 More than one strategy: A closer examination of the relationship between deep acting and key employee outcomes

Chapter 4 Unpacking deep acting: An experiment on the intra-and interpersonal effects of three deep acting strategies

Chapter 5 Going beyond deep and surface acting: A bottom-up investigation of emotional labor strategies

Chapter 6 General discussion

\begin{tabular}{|c|c|c|}
\hline \multirow[t]{5}{*}{ Appendix } & Summary & 179 \\
\hline & Bottom-up emotional labor strategies & 183 \\
\hline & Impact paragraph & 196 \\
\hline & Acknowledgements & 199 \\
\hline & Curriculum vitae & \\
\hline
\end{tabular}

Curriculum vitae 

CHAPTER 1

General introduction 

A few months ago, I participated in a teaching development workshop. During the workshop, teachers were asked to share difficult encounters with students (e.g., conflicts) and their strategies to deal with these challenges. The most memorable story was of a student who fell asleep during a neuro-psychology tutorial. As a result, the teacher was experiencing a mix of negative emotions: anger, disappointment, and a sense of incompetence. However, she had to control her negative feelings in order to continue teaching in a professional manner. She suppressed her negative feelings and acted as if she was calm. Yet, this was difficult for her, and she felt even worse at the end of the class. Could she have acted differently and would she then have felt better in the end? More generally, what strategies can employees use to manage their emotions at work during interpersonal encounters and what are the consequences of these strategies? These questions are examined in this dissertation.

As illustrated by the situation above, most employees, including but not limited to teachers, cashiers, customer service employees, nurses, and doctors, must regulate their emotions as an integral part of their jobs. This is called emotional labor (Hochschild, 1983). For example, teachers need to stay calm when dealing with difficult students, cashiers have to greet all customer with a smile, and doctors and nurses need to express empathy towards their patients.

During the past three decades, a large body of research on emotional labor has emerged. Most of these studies focused on two emotional labor strategies: surface acting and deep acting (Grandey, 2000; Grandey \& Gabriel, 2015; Hochschild, 1983). When engaging in surface acting, employees pretend to have organizationallyrequired emotions or hide their undesirable emotions. In contrast, when engaging in deep acting, employees attempt to actually feel the emotions they have to show as part of their job. In the example above, the tutor engaged in surface acting, as she adapted her outward expression to look calm while in reality she felt very emotional. Alternatively, she could have engaged in deep acting by making use of one of the following three specific emotion regulation strategies (Grandey, 2000). She could have thought (a) that the fatigue of the student is caused by personal problems (perspective-taking), (b) that the situation is not all that bad as all other students are enthusiastic about participating in her class (positive reappraisal), or (c) about her upcoming holiday which provides a pleasant distraction (attentional deployment). 
Each of these three forms of deep acting regulates inner feelings and results in expressions mandated by the job (Grandey, 2000).

Given this fundamental distinction between surface and deep acting, researchers have compared their consequences for employees' well-being and performance. The current theory distinguishes between proximal outcomes and more distal outcomes of surface and deep acting (Holman, Martínez-Iñigo, \& Totterdell, 2008; Hülsheger \& Schewe, 2011; Wang et al., 2017). Several key outcomes have been proposed to act as proximal consequences through which surface acting and deep acting eventually influence more distal outcomes such as strain, job satisfaction, task performance, or customer satisfaction (Holman et al., 2008; Hülsheger \& Schewe, 2011; Wang et al., 2017). These proximal outcomes include resource depletion, self-authenticity, positive/negative affect, rewarding interactions with customers, customer-perceived authenticity, and customers' service appraisal (Holman et al., 2008; Hülsheger \& Schewe, 2011; Wang et al., 2017). Empirical research has supported the proposed connections, demonstrating that surface and deep acting are differentially relate to well-being and performance outcomes (e.g., Brotheridge \& Lee, 2002; MartínezIñigo, Totterdell, Alcover, \& David, 2007). Yet, empirical investigations of the proximal outcomes and proposed mechanisms driving relationships with distal outcomes have been scarce.

Meta-analyses of studies examining the impact of chronic use of deep acting and surface acting found that surface acting had a robust positive relationship with distal strain outcomes (e.g., emotional exhaustion) while deep acting displayed weak and inconsistent relationships with strain outcomes (Hülsheger \& Schewe, 2011; MesmerMagnus, DeChurch, \& Wax, 2012; Yin, Huang, \& Chen, 2019). A similar pattern of results was found in daily diary studies investigating short-term within-person associations of deep and surface acting with employee outcomes. For example, while within-person daily surface acting was related to higher levels of resource depletion, deep acting was not related to depletion (e.g., Huppertz, Hülsheger, De Calheiros Velozo, \& Schreurs, 2020; Uy, Lin, \& llies, 2017). Likewise, surface acting appears to be a less optimal strategy than deep acting for performance outcomes (Grandey, 2003; Hülsheger \& Schewe, 2011). It was negatively associated with task and emotional performance (Hülsheger $\&$ Schewe, 2011). In contrast, deep acting was related to greater emotional performance, while it was not related to task performance (Hülsheger \& Schewe, 2011). 
Although prior research on emotional labor has increased our understanding of emotional labor strategies and their potential consequences, there are three critical research gaps in the literature. First, while surface acting seems to have a robust negative association with employees' well-being and their performance, research on consequences of deep acting has provided mixed results and therefore, deep acting is less well understood. For example, some studies suggest that deep acting promotes employees' well-being (e.g., Scott \& Barnes, 2011) while other studies have not observed such an effect (e.g., Judge, Woolf, \& Hurst, 2009). This is troublesome because this mixed evidence restricts our understanding of the consequences and practical value of deep acting. One reason for these mixed findings may be the assessment of deep acting (Hülsheger \& Schewe, 2011). Previous studies have often investigated deep acting as a unitary construct without specifying specific emotion regulation strategies. For example, the widely-used deep acting scale includes items like, "I try to actually experience the emotions that I must show" and "I really try to feel the emotions I have to show as part of my job" (Brotheridge \& Lee 2003). Yet, such items do not capture the multifaceted nature of deep acting (Hülsheger \& Schewe, 2011). To engage in deep acting, employees can rely on various strategies (Grandey, 2000). For example, they may adopt the customer's perspective, find positive meaning in a negative situation or distract themselves with a happy memory (Grandey, 2000). Combining these different strategies into a single construct may mask important (positive or negative) effects of individual strategies on key proximal outcomes (Hülsheger \& Schewe, 2011). Moreover, the typical deep acting scale (Brotheridge \& Lee 2003) confounds the motivation to engage in emotion regulation (e.g., motivation to change feelings) with the actual cognitive-emotional strategies used (Grandey \& Gabriel, 2015). Taken together, a multi-dimensional perspective on deep acting that takes into account possible differential consequences of specific deep acting strategies is needed to better understand the deep acting construct. Doing so may provide insights into the relationship of deep acting with key indicators of well-being and performance and distinguish aspects of deep acting that foster them from those that do not. Such insights will eventually help resolve contradictory findings observed in prior research on deep acting. 
Second, despite continued theoretical and empirical interest in understanding the outcomes of deep acting (Grandey, \& Gabriel, 2015), the causal role of deep acting has been rarely demonstrated. This is problematic because the question of whether deep acting impacts well-being and performance-related outcomes cannot be conclusively answered without causal evidence. From a practical perspective, this lack of causal evidence is also problematic as it limits the development of deep acting training programs that may benefit employees and organizations.

Based on existing cross-sectional relationships, we cannot conclude whether deep acting actually causes the studied outcomes or whether the causal arrow goes the other way around. For example, the cross-sectional finding that deep acting is positively related to rewarding customer treatment (Zhan, Wang, \& Shi, 2016) could also be due to deep acting strategies being chosen when interacting with nice clients, rather than deep acting impacting the customer interaction. Similarly, employees may use deep acting when they already feel positive in pleasant interactions to reciprocate customer's positive behavior (Diefendorff, Gabriel, Nolan, \& Yang, 2019; Totterdell \& Holman, 2003). Moreover, cross-sectional findings may underestimate the role of situational or dispositional factors that could act as confounding variables in the relationships between deep acting and studied outcomes. For example, it might be that customer familiarity increases both deep acting and rewarding interactions, creating a spurious relationship between deep acting and rewarding interactions.

Experimental research is needed to observe the true nature of the relationship between deep acting and emotional labor outcomes. Experimental studies also allow testing whether different specific deep acting strategies show differential causal links with key proximal outcomes such as resource depletion, self-authenticity, positive/ negative affect, customer-perceived authenticity, or customers' service appraisal. Moreover, establishing the causal links between specific deep acting strategies and these proximal outcomes provides the necessary input for eventually developing a robust theoretical model on the consequences of deep acting.

Third, by focusing mostly on deep acting and surface acting researchers may have overlooked other emotional labor strategies that employees can use when engaging in emotional labor. For example, going back to the teacher example, she could have 
used a range of other strategies instead of surface acting or deep acting. For example, she could have interrupted the class and talked to the student in private to help the student solve his/her problems, or she could have encouraged the student to see the situation from her perspective, or she could have reminded the student about her expectation that students should actively participate during class discussions. Each of these alternative strategies could help the teacher to regulate her emotions but they do not fall within the broad classes of deep acting or surface acting. It is thus likely that there are emotional labor strategies that are beyond the scope of deep and surface acting. To fully understand the construct of emotional labor, a systematic and complete taxonomy emotional labor strategies is of key importance.

At least two research lines suggest what these additional regulation strategies may entail. First, Gross's (1998) theoretical model on emotion regulation covers two regulation strategies that have been understudied in the context of emotional labor: situation selection (i.e., seeking or avoiding situations that will cause particular emotions) and situation modification (i.e., changing the situation in order to decrease its emotional impact; Gross, 1998). Diefendorff and colleagues (2008) provided first evidence that these situation-targeted strategies are frequently employed in emotional labor contexts. Concrete examples of these strategies include a waiter who chooses to interact with a nice regular customer while avoiding a rude customer who just walked in, or a teacher who focuses on pleasant and engaged students in an interactive course while ignoring the non-motivated students.

Second, research on interpersonal emotion regulation (outside the organization sciences) suggests that individuals can regulate their own emotions by regulating their interaction partners' emotions (Swerdlow \& Johnson; 2020; Williams, Morelli, Ong, $\&$ Zaki, 2018). Considering the interpersonal nature of emotional labor, employees may utilize interpersonal regulation strategies when engage in emotional labor. For example, a nurse may comfort an anxious patient, and the anxiety reduction in the patient may subsequently help the nurse to stay calm herself and manage her own negative feelings. Yet, interpersonal strategies have hardly been considered in the context of emotional labor, neither theoretically, nor empirically.

Overall, these theoretical frameworks show that there may be many emotional labor strategies that are yet to be studied. Therefore, there is a clear need for a new 
taxonomy of emotional labor strategies that comprehensively describes employees' repertoire of emotional labor strategies. Such a taxonomy would provide a clearer and richer overview of emotional labor strategies, and ultimately of their consequences.

The current dissertation aims to fill these three critical gaps in the literature. Specifically, it will address the following questions:

1) Do mixed findings on deep acting stem from its multidimensional nature? Do different strategies (perspective-taking, positive reappraisal, and attentional deployment) involved in deep acting differentially relate to key proximal outcomes (i.e., resource depletion, self-authenticity, rewarding interactions with customers) between and within-persons?

2) Do specific deep acting strategies causally impact key outcomes (i.e., resource depletion, self-authenticity, positive/negative affect, rewarding interactions with customers, customer-perceived authenticity, and customers' service appraisal)? Can deep acting strategies easily be manipulated in a lab context?

3) Are there emotional labor strategies that employees use that go beyond deep and surface acting? How does a complete taxonomy of emotional labor strategies look like?

In the following section, I will elaborate on how the current dissertation will address the three identified gaps and on the importance of filling these gaps for the emotional labor literature.

\section{Dissertation Outline}

The main body of this dissertation consists of four chapters. In Chapter 2, a literature review is presented that forms the foundation of the three empirical chapters of this dissertation. This review highlights the knowns and unknowns about emotional labor strategies and their outcomes. In Chapter 3, we ${ }^{1}$ aim to deepen the current knowledge on deep acting. We argue that previous inconsistent findings on deep acting can be partially explained by the fact that the broad category of deep acting encompasses fundamentally different emotion regulation strategies. Specifically, in this chapter, we examine the association between three specific deep acting strategies (perspective-

1 I used the term "we" as the empirical chapters were conducted with co-authors 
taking, positive reappraisal, and attentional deployment) and three key proximal outcomes (resource depletion, self-authenticity, and rewarding interactions) using a daily diary study. Chapter 4 examines the impact of the same three deep acting strategies but this time using an experimental approach. In a travel agency simulation, we manipulate perspective-taking, positive reappraisal, and attentional deployment and test their impact on employees' affective state, depletion, and authenticity as well as customers' perception of authenticity and service appraisals. In Chapter $\mathbf{5}$, we argue that employees' emotional labor strategy repertoire includes far more than deep acting and surface acting only. In this chapter we develop the first bottom-up taxonomy of emotional labor strategies. Using semi-structured interviews, we first collect information on a wide range of emotional labor strategies and subsequently categorize these strategy statements based on their similarities. This approach can result in a new taxonomy of emotional labor strategies consisting of both established as well as novel emotional labor categories. Finally, Chapter 6 presents a summary of the empirical findings and discussion of these findings' theoretical, methodological, and practical contributions.

\section{General Contributions}

This dissertation advances the field of emotional labor in several ways. First, it helps refine emotional labor theory (Grandey, 2000). Specifically, Chapter 3 and 4 empirically test whether deep acting involves fundamentally different strategies that have different relationships with key employee outcomes. This multi-dimensional perspective on deep acting may yield unique relationships of different deep acting strategies with key emotional labor outcomes. Such findings may increase our understanding of the nature of the deep acting construct as well as its outcomes.

Second, the current fine-grained investigation of deep acting may explain past inconsistent findings on the deep acting-wellbeing relationship (Hülsheger \& Schewe, 2011). Despite the clear theoretical distinctions between specific deep acting strategies, past research treated deep acting as a unitary construct, which complicated predictions about deep acting outcomes. By isolating the underlying strategies, the present dissertation tests whether inconsistencies in previous research might be partially attributed to the fact that perspective-taking, positive reappraisal, and attentional deployment have different links with well-being. 
Third, Chapter 5 extends current emotional labor theories by going beyond deep and surface acting. Our bottom-up taxonomy of emotional labor strategies can foster a more comprehensive understanding of emotional labor. Furthermore, it may stimulate further theoretical and empirical research on understudied and unrecognized emotional labor strategies.

Fourth, this dissertation offers several methodological advancements to emotional labor research. We employ three different approaches, which allow us to overcome previous methodological shortcomings and obtain more robust conclusions:

(a) Using a daily diary approach in Chapter 3, we investigate the relationships between deep acting strategies and key emotional labor outcomes both within and between persons. Testing the relationships at both levels allows us to see the short-term within-person and long-term between-person associations between deep acting strategies and important outcomes. Overall, this provide a more detailed understanding of the consequences of deep acting.

(b) Using an experimental approach in Chapter 4, we investigate deep acting strategies as possible causes of key outcomes in a simulated customer-service setting. This overcomes the limitations associated with the observational designs that have thus far dominated the emotional labor domain. The experimental protocol we developed may also inspire future experimental work who can build on our protocol and further refine it.

(c) Using a bottom-up approach in Chapter 5, we go beyond deep and surface acting and provide a more comprehensive understanding of emotional labor strategies that could be obtained when relying solely on top-down theoretical approaches.

Finally, this dissertation is valuable from a practical perspective. It is vital to understand (consequences of) specific emotional labor strategies, as these findings provide critical input to training programs aimed at optimizing emotional labor outcomes. The inconclusive results on the consequences of deep acting in the literature present a major challenge to translate current empirical findings into useful practices and training programs. Our multidimensional focus on deep acting may reveal a particularly adaptive deep acting strategy for employees' well-being and performance, and service employees can be encouraged to especially train that particular strategy. In fact, the fundamental emotion regulation literature showed that perspective-taking, positive reappraisal and attentional deployment can all be trained, making them 
suitable for emotional labor intervention and training (for a review, Denny, 2020). Finally, our bottom-up taxonomy of emotional labor strategies may allow extending current training programs by going beyond deep acting strategies, which, ultimately may augment the effectiveness of training programs. 


\section{References}

Brotheridge, C. M., \& Lee, R. T. (2002). Testing a conservation of resources model of the dynamics of emotional labor. Journal of Occupational Health Psychology, 7(1), 57-67. https://doi. org/10.1037/1076-8998.7.1.57

Brotheridge, C. M., \& Lee, R. T. (2003). Development and validation of the emotional labour scale. Journal of Occupational and Organizational Psychology, 76(3), 365-379. https://doi. org/10.1348/096317903769647229

Denny, B. T. (2020). Getting better over time: A framework for examining the impact of emotion regulation training. Emotion, 20(1), 110-114. https://doi.org/10.1037/emo0000641

Diefendorff, J. M., Gabriel, A. S., Nolan, M. T., \& Yang, J. (2019). Emotion regulation in the context of customer mistreatment and felt affect: An event-based profile approach. Journal of Applied Psychology, 104(7), 965-983. https://doi.org/10.1037/apl0000389

Diefendorff, J. M., Richard, E. M., \& Yang, J. X. (2008). Linking emotion regulation strategies to affective events and negative emotions at work. Journal of Vocational Behavior, 73, $498-508$. http://dx.doi.org/10.1016/j.jvb.2008.09.006

Grandey, A. A. (2000). Emotion regulation in the workplace: A new way to conceptualize emotional labor. Journal of Occupational Health Psychology, 5, 95-110. http://dx.doi.org/10.1037/10768998.5.1.95

Grandey, A. A. (2003). When "the show must go on": Surface acting and deep acting as determinants of emotional exhaustion and peer-rated service delivery. Academy of Management Journal, 46(1), 86-96. https://doi.org/10.2307/30040678

Grandey, A. A., \& Gabriel, A. S. (2015). Emotional labor at a crossroads: Where do we go from here? Annual Review of Organizational Psychology and Organizational Behavior, 2, 323-349. https:// doi.org/10.1146/annurev-orgpsych-032414-111400

Gross, J. J. (1998). Antecedent- and response-focused emotion regulation: Divergent consequences for experience, expression, and physiology. Journal of Personality and Social Psychology, 74(1), 224-237. https://doi.org/10.1037/0022-3514.74.1.224

Hochschild, A. R. (1983). The managed heart: Commercialization of human feeling. Berkeley, CA: University of California Press.

Holman, D., Martinez-iñigo, D., \& Totterdell, P. (2008). Emotional labour and employee well-being: An integrative review. In N. Ashkanasy \& C. L. Cooper (Eds.), Research companion to emotion in organizations (pp. 301-315). Northampton, MA: Edward Elgar Publishing. http://dx .doi. org/10.4337/9781848443778.00029

Hülsheger, U. R., \& Schewe, A. F. (2011). On the costs and benefits of emotional labor: A meta- 
analysis of three decades of research. Journal of Occupational Health Psychology, 16(3), 361389. https://doi.org/10.1037/a0022876

Huppertz, A. V., Hülsheger, U. R., De Calheiros Velozo, J., \& Schreurs, B. H. (2020). Why do emotional labor strategies differentially predict exhaustion? Comparing psychological effort, authenticity, and relational mechanisms. Journal of Occupational Health Psychology, 25(3), 214-226. https:// doi.org/10.1037/ocp0000179

Judge, T. A., Woolf, E. F., \& Hurst, C. (2009). Is emotional labor more difficult for some than for others? A multi-level, experience sampling study. Personnel Psychology, 62, 57- 88. http:// dx.doi.org/10.1111/j.1744-6570.2008.01129.x

Martínez-Iñigo, D., Totterdell, P., Alcover, C. M., \& Holman, D. (2007). Emotional labour and emotional exhaustion: Interpersonal and intrapersonal mechanisms. Work \& Stress, 21(1), 30-47. https://doi. org/10.1080/02678370701234274

Mesmer-Magnus, J. R., DeChurch, L. A., \& Wax, A. (2012). Moving emotional labor beyond surface and deep acting. Organizational Psychology Review, 2, 6 -53. http://dx.doi. org/10.1177/2041386611417746

Scott, B. A., \& Barnes, C. M. (2011). A multilevel field investigation of emotional labor, affect, work withdrawal, and gender. Academy of Management Journal, 54, 116 -136. http://dx.doi. org/10.5465/amj.2011.59215086

Swerdlow, B. A., \& Johnson, S. L. (2020). The Interpersonal Regulation Interaction Scale (IRIS): A multistudy investigation of receivers' retrospective evaluations of interpersonal emotion regulation interactions. Emotion. Advance online publication. https://doi.org/10.1037/emo0000927

Totterdell, P., \& Holman, D. (2003). Emotion regulation in customer service roles: Testing a model of emotional labor. Journal of Occupational Health Psychology, 8(1), 55-73. https://doi. org/10.1037/1076-8998.8.1.55

Uy, M. A., Lin, K. J., \& Ilies, R. (2017). Is it better to give or receive? the role of help in buffering the depleting effects of surface acting. Academy of Management Journal, 60, 1442-1461. http:// dx.doi.org/10.5465/amj .2015.0611

Wang, Z., Singh, S. N., Li, Y. J., Mishra, S., Ambrose, M., \& Biernat, M. (2017). Effects of employees' positive affective displays on customer loyalty intentions: An emotions-as-social-information perspective. Academy of Management Journal, 60(1), 109-129. https://doi.org/10.5465/ amj.2014.0367

Williams, W. C., Morelli, S. A., Ong, D. C., \& Zaki, J. (2018). Interpersonal emotion regulation: Implications for affiliation, perceived support, relationships, and well-being. Journal of Personality and Social Psychology, 115(2), 224-254. https://doi.org/10.1037/pspi0000132

Yin, H., Huang, S., \& Chen, G. (2019). The relationships between teachers' emotional labor and their 
burnout and satisfaction: A meta-analytic review. Educational Research Review, 28, 1-18. https:// doi.org/10.1016/j.edurev.2019.100283

Zhan, Y., Wang, M., \& Shi, J. (2016). Interpersonal process of emotional labor: The role of negative and positive customer treatment. Personnel Psychology, 69(3), 525-557. https://doi.org/10.1111/ peps.12114 
CHAPTER 2

\section{A review of emotional labor research: \\ The road behind and the road ahead}




\section{Abstract}

Research on emotional labor has grown exponentially over the last three decades. This research has shown that employees engage in different strategies (especially deep and surface acting) to manage their emotions in client interactions, and that the particular emotional labor strategies they use influences their well-being and performance. However, critical but unresolved questions have remained. Why did previous studies of deep acting outcomes produce inconsistent findings? Is it due to the multidimensional nature of deep acting? Are different subtypes of deep acting (causally) differently associated with emotional labor outcomes? Do surface acting and deep acting exhaustively describe employees' repertoire of emotional labor strategies? In this chapter, we, therefore, review the current state of theoretical and methodical knowledge and identify how researchers can advance the field of emotional labor.

Keywords: deep acting, emotional labor, emotion regulation, surface acting 
An airline company of Garuda Indonesia considers different options to remove flight attendants' face masks. The CEO reported that "Many customers have complained about the flight attendants wearing masks as [the passengers] cannot see whether or not the [flight attendants] are smiling or frowning." (Slotnick, 2020). This situation perfectly illustrates the individual, organizational and societal relevance of emotional labor, which refers to controlling one's emotions for work purposes (Grandey, 2000). Emotional labor poses challenges for employees, organizations and society at large. For employees, emotional labor is an effortful process as adjusting one's emotions often requires resources (Grandey, 2000; 2003; Hochschild, 1983). It can also be costly as emotional labor may threaten employees' well-being and even their sense of self (Ashforth \& Humphrey, 1993; Brotheridge \& Lee, 2003).

For organizations, emotional labor presents a challenge as they need to find the right balance between the well-being of their employees and the satisfaction of their customers. On the one hand, due to its effortful nature, emotional labor may threaten employees' health and well-being, which may eventually lead to turnover (Chau, Dahling, Levy, Diefendorff, 2009; Goodwin, Groth, Frenkel, 2011; Grandey, 2000). On the other hand, emotional labor is crucial for customer satisfaction, which is key for organizations' survival and success (Hallowell, 1996; Humphrey, Ashforth, Diefendorff, 2015; Luo \& Bhattacharya, 2006).

For society, the challenge is to respond to the growing demands of the emotional labor economy. More than $70 \%$ of employees in developed economies, including European countries, are working in service jobs (The World Bank, 2020). That means more and more employees are facing emotional labor demands. Moreover, emotional labor can have a negative effect not only on employees' well-being, but also on that of their family members (Sanz-Vergel, Rodríguez-Muñoz, Bakker, \& Demerouti, 2012). Consequently, psychological health care demands may grow in parallel with the increase in emotional labor jobs. Moreover, emotional labor is essential for the competitive advantage of service companies, and these companies' success may ultimately influence societal welfare (Sutcliffe \& Vogus, 2003).

Coined by Arlie Hochschild in 1983, emotional labor has generated a great deal of interest in practice and various research fields (e.g., psychology, organizational behavior, and sociology). Considerable progress has been made in outlining 
emotional labor strategies and their consequences for employees and organizations. Past studies have mostly focused on the two broad emotional labor strategies of surface and deep acting and their consequences for employees' well-being and performance. Specifically, surface acting (i.e., faking the expected displays) has been found to be a predictor of decreased well-being and performance (for metaanalysis, Hülsheger $\&$ Schewe, 2011). In contrast, deep acting (trying to feel and show the expected displays) has been found to be a predictor of increased performance although, overall, evidence is rather mixed, especially regarding its relationship with well-being (for meta-analysis, Hülsheger \& Schewe, 2011).

Understanding emotional labor strategies and their consequences is essential to address the individual, organizational and societal challenges of emotional labor. However, the current state of knowledge about emotional labor suggests that we might have overlooked important issues. For example, why does deep acting show inconsistent relationships with employee outcomes? How can we obtain causal evidence to examine whether emotional labor actually impacts employee outcomes (rather than the other way around)? Does the deep acting-surface acting dichotomy suffice to capture all possible emotional labor strategies? Answering these questions is of vital importance to advance our current understanding of emotional labor.

The present review has two goals. The first aim is to provide an overview of emotional labor research to date. The second aim is to identify key research gaps in the emotional labor domain. In our review, we concentrate on the impact of the two main emotional labor strategies (deep acting and surface acting) because they have been often studied and have deepened our understanding of emotional labor. To make the review tractable, we will focus on the impact of these two strategies on the following key outcome variables: resource depletion, self-authenticity, positive/negative affect, rewarding interactions with customers, customer-perceived authenticity, or customers' service appraisal. We selected these outcome variables because of their theoretical and practical value. From a theoretical perspective, they are wellestablished proximal outcomes of emotional labor strategies that precede more distal well-being and performance outcomes (Holman, Martínez-Iñigo, \& Totterdell, 2008; Hülsheger \& Schewe, 2011; Wang et al., 2017). Studies on these outcomes are rare but have enabled deeper explanations of the long-term and short-term consequences 
of deep and surface acting (Huppertz, Hülsheger, De Calheiros Velozo, \& Schreurs, 2020; Zhan, Wang, \& Shi, 2016). For example, they can advance our understanding of the dynamic mechanisms underlying the effects of surface and deep acting (e.g., Huppertz et al., 2020; Zhan et al., 2016). Moreover, a better understanding of these outcomes can facilitate theoretically grounded investigations. From a practical perspective, focusing on these proximal outcomes can inform practitioners and researchers alike about why the desirable or undesirable more long-term effects of deep and surface acting occur. This may also guide practitioners in their endeavors to design targeted occupational health interventions.

We organize the review as follows: First, we provide a short historical overview of the different approaches used in emotional labor research. Next, we will review research on the two dominant emotional labor strategies in the literature: deep acting and surface acting. We will focus on the measurement of these two strategies and summarize empirical evidence on the association of these emotional labor strategies with the mentioned key proximal outcomes. Finally, we will discuss research gaps and suggest avenues to further improve emotional labor research.

\section{What is Emotional Labor?}

In 1983, sociologist Arlie Hochschild brought emotional labor to scientific attention with her book "The Managed Heart: Commercialization of Human Feeling". She argued that the rise of the service economy created many occupations where employees engage in emotional labor in exchange for a wage, such as customer service and health care jobs. These emotional labor occupations were characterized by three features: 1) frequent contact with clients (customers, patients), 2) the requirement of generating organizationally desired reactions (e.g., positive customer emotions), and 3 ) the control of client interactions via organizational practices (e.g., display rules or rewards; Hochschild, 1983).

At the core of Hochschild's (1983) approach, emotional labor is seen as occupational requirements. This approach suggests that employees dramaturgically act to create the expected emotions (Grandey, Diefendorff, \& Rupp, 2013). In particular, she focused on two acting techniques, namely, surface acting and deep acting. Surface acting refers to matching outward expressions with the emotional expectations of 
the job, while deep acting refers to deeply experiencing and showing the expected emotions (Hochschild, 1983).

Although the fundamental arguments of Hochschild (1983) have continued to shape emotional labor research, different theoretical interpretations of emotional labor have developed across different disciplines (Grandey et al., 2013). Building on Hochschild's (1983) approach, organizational behavior researchers adopted a more behavioral perspective to study emotional labor (Ashforth \& Humphrey, 1993; Grandey et al., 2013). They studied emotional labor as emotional displays and only focused on employees' emotional observable displays (e.g., greeting and smiling, Ashforth \& Humphrey, 1993), disregarding employees' feelings (Grandey et al., 2013). To create job-congruent displays, employees were suggested to fake in good faith (internalizing display rules) or fake in bad faith (following display rules without internalizing them, Rafaeli \& Sutton, 1987).

Another perspective considers emotional labor as intrapsychic experiences (Grandey et al., 2013). According to this view, emotional labor involves effortful management of feelings to create organizationally required displays (Grandey, 2000; Grandey et al., 2013). Therefore, emotional labor was defined as: "emotional labor is the process of regulating both feelings and expressions for organizational goals" (Grandey, 2000, p. 97). This operationalization of emotional labor as emotion regulation has become mainstream in the emotional labor literature, particularly in psychology (Grandey et al., 2013). The present review, therefore, mainly focuses on this perspective.

This perspective links Hochschild's (1983) deep and surface acting to emotion regulation strategies of the process model of emotion regulation (Gross, 1998). Grandey (2000) argued that deep acting relies on antecedent-focused emotion regulation where employees influence their undesirable emotions before they escalate (Grandey, 2000; Gross, 1998). Consequently, the resulting expressions are naturally aligned with jobs' expectations (Grandey, 2000). In contrast, surface acting relies on response-focused emotion regulation where employees only manipulate their outward expressions after their emotions are already stronger (Grandey, 2000; Gross, 1998). 


\section{What Emotional Labor Strategies are Most Frequently Studied?}

Undoubtedly, the most studied emotional labor strategies are deep acting and surface acting (Grandey \& Gabriel, 2015; Grandey \& Melloy, 2017) although some researchers have also acknowledged the existence of automatic regulation or the expression of naturally felt emotions (Diefendorff, Croyle, \& Gosserand, 2005; Scott, Lennard, Mitchell, \& Johnson, 2020). Yet, our focus will be on effortful emotion regulation strategies and therefore on deep and surface acting. As mentioned above, the distinction into deep acting and surface acting parallels the distinction between antecedent-focused and response-focused emotion regulation put forth by Gross's (1998) in the general emotion regulation literature. Let's consider the example when a customer service employee is getting annoyed by an indecisive customer during a long interaction. To deep act, she can engage in antecedent-focused emotion regulation. Although deep acting has been typically considered as a uniform strategy, the service employee can in fact use three antecedent-focused strategies: perspective-taking, positive reappraisal and attentional deployment (Grandey, 2000; Hochschild, 1983; Rupp, McCance, Spencer, \& Sonntag, 2008). In perspective-taking, she puts herself in the indecisive customers' shoes to modify her emotional state. She may think that it may take some time to decide for a meticulous person. In positive reappraisal, she makes positive interpretations about the situation (Grandey, 2000; Gross, 1998). In this case, the service employee can see the interaction with the indecisive customer as a challenge (e.g., a chance to improve her selling techniques). Finally, in attentional deployment, she shifts her attention to objects or thoughts that can positively influence her emotional state (Grandey, 2000; Gross, 1998). She may recall happy moments with her child, which helps her feel more positive. To surface act, she can engage in response-focused emotion regulation and masks her annoyance with a smile. (Grandey, 2000).

\section{How Has Emotional Labor been Studied?}

To measure emotional labor strategies and associated outcomes self-report scales have been most often used. The first generation of emotional labor research treated it as a stable construct. These studies were cross-sectional in nature and utilized traitlevel measures (for meta-analysis, Hülsheger \& Schewe, 2011). In these studies deep acting measures capture employees' general efforts to modify their true feelings, 
while surface acting measures capture the degree to which employees hide and fake emotional expressions (Brotheridge $\&$ Lee, 2003). For example, deep acting is measured by items like "I try to actually experience the emotions that I must show" and "I really try to feel the emotions I have to show as part of my job" (Brotheridge $\&$ Lee, 2003). Surface acting is measured by items like "I pretend to have emotions that I don't really have" and "I hide my true feelings about a situation" (Brotheridge $\&$ Lee, 2003). This static approach has revealed that the chronic use of emotional labor strategies is related to emotional exhaustion, job satisfaction, and emotional performance (Hülsheger \& Schewe, 2011).

The second generation of emotional labor studies adopted a more dynamic approach recognizing that the use of emotional labor strategies is variable within individuals over time and that this within-individual variation might have implications for emotional labor outcomes (e.g., Beal, Trougakos, Weiss, \& Green, 2006; Judge, Woolf, \& Hurst, 2009; Scott $\&$ Barnes, 2011). In contrast to cross-sectional studies, within-person studies (daily-diary and experience-sampling studies) reveal how a person varies from his/her own average use of emotional labor strategies across time and how this variation relates to key outcomes variables such as resource depletion, self-authenticity, and rewarding interactions with customers (Huppertz et al., 2020; Zhan et al., 2016). To measure within-person variation in emotional labor strategies, these second generation studies adapted the trait-level measures (Brotheridge $\&$ Lee, 2003) to a daily context by modifying the wording of items. They also shortened the list of items to decrease participants' burden. This dynamic within-person focus on emotional labor is becoming more dominant in the literature. Researchers have argued that within-person investigations can more closely capture the true nature of emotional labor as it is inherently a dynamic process (Beal \& Trougakos, 2013; Beal et al., 2006). Indeed, emotions and emotion regulation change over time, which makes it critical to study the dynamic components of emotional labor.

\section{What are the Consequences of Emotional Labor?}

The main focus of emotional labor research has been on the consequences of emotional labor strategies for employees' well-being and performance. By drawing on well-established theories (i.e., conservation of resources and emotions as social information model), researchers have made a distinction between proximal and more 


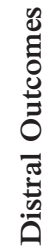
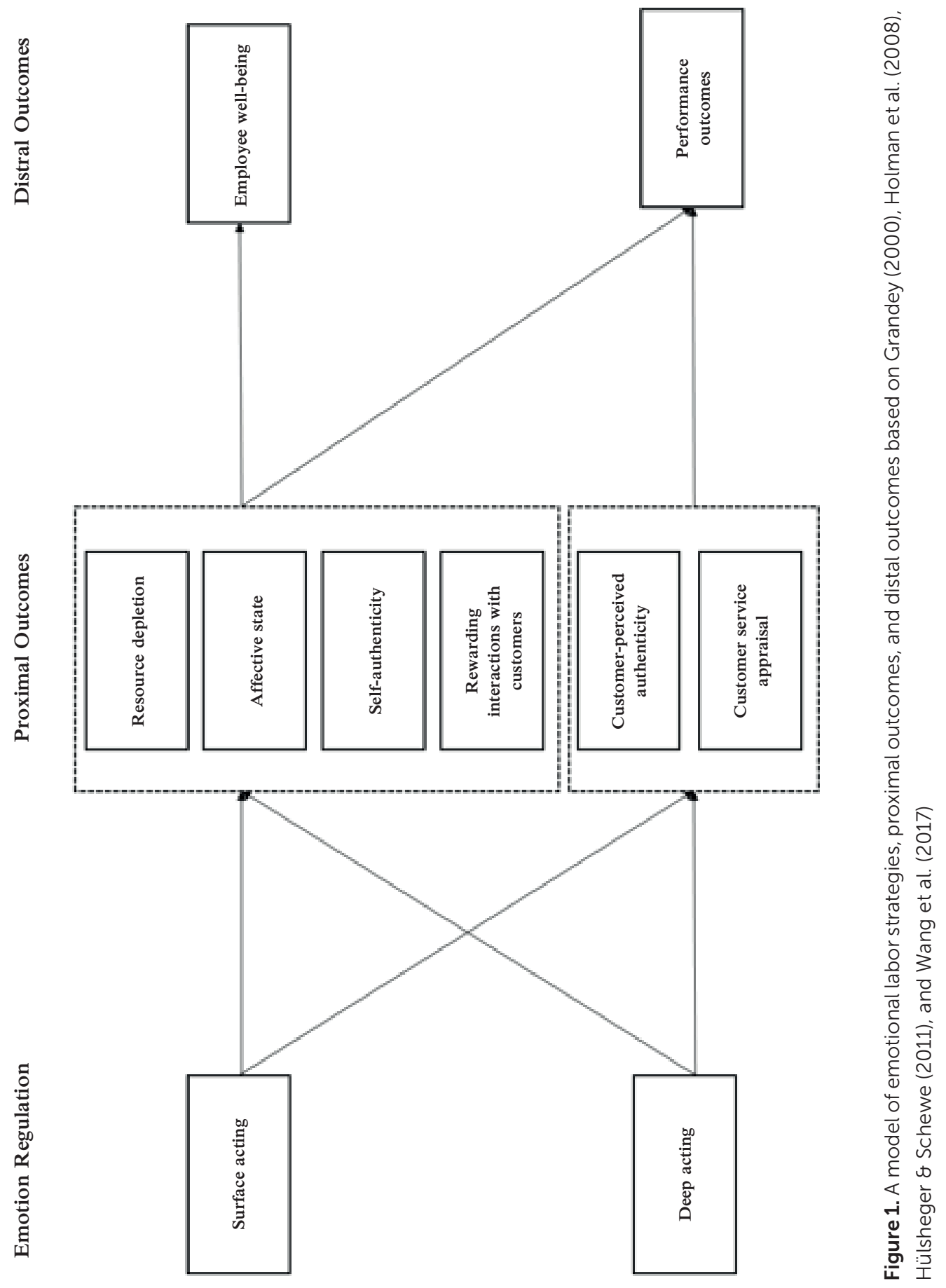
distal outcomes of emotional labor (Holman et al., 2008; Hülsheger \& Schewe, 2011; Wang et al., 2017). More specifically, the following proximal outcomes have been identified: resource depletion, positive/negative affect, self-authenticity, customerperceived authenticity, rewarding interaction with customers, and customer service appraisal (Holman et al., 2008; Hülsheger \& Schewe, 2011; Wang et al., 2017). These key outcomes have been found to connect deep and surface acting to more distal individual and organizational-related outcomes such as, emotional exhaustion/ burnout, job satisfaction, performance, counterproductive work behaviors, customer incivility and customer satisfaction (Deng, Walter, Lam, \& Zhao, 2017; Hülsheger \& Schewe, 2011; Zhan, Luo, Ding, Zhu, \& Guo, 2021; Zhan et al., 2016).

Figure 1 illustrates how surface and deep acting relate to proximal and in turn to distal outcomes. In the next section, we elaborate on the links of surface and deep acting with these proximal outcomes by describing relevant theoretical and empirical research.

\section{Resource Depletion}

Resource depletion is both an acute and possible chronic result of emotional labor characterized by feelings of fatigue (Beal et al., 2013; Brotheridge \& Lee, 2002; Trougakos, Beal, Cheng, Hideg, \& Zweig, 2015). According to the conservation of resources theory (Hobfoll, 2002; 2011), surface acting and deep acting draw upon employees' resources as regulating emotions is effortful (Brotheridge $\&$ Lee, 2002). If employees cannot replenish their consumed resources, they face detrimental consequences, such as burnout (Brotheridge $\&$ Lee, 2002).

Although emotional labor consumes resources, deep acting has the potential to generate new resources, such as positive or authentic emotional feeling states (Brotheridge \& Lee, 2002; Côté, 2005; Grandey \& Melloy, 2017; Hülsheger \& Schewe, 2011). In contrast, surface acting fails to build up such resources (Brotheridge \& Lee, 2002; Côté, 2005; Grandey \& Melloy, 2017; Hülsheger \& Schewe, 2011). Consequently, when engaging in deep acting, employees both consume and build resources, and can keep their resources in check. In contrast, when engaging in surface acting, employees only experience resource loss (Brotheridge \& Lee, 2002; Grandey \& Melloy, 2017). 
Although the resource-draining nature of daily and habitual surface acting has been consistently demonstrated, empirical evidence is less robust when it comes down to the consequences of deep acting (Hülsheger \& Schewe, 2011; Huppertz, Hülsheger, De Calheiros Velozo, \& Schreurs, 2020). For example, some have suggested that resource gain outweighs resource loss in deep acting by showing a negative link between deep acting and depletion or exhaustion (e.g., Deng et al., 2017; Xanthopoulou, Bakker, Oerlemans, \& Koszucka, 2018). However, others have not found any link between deep acting and resource depletion (e.g., Huppertz et al. 2020; Sayre, Grandey, \& Chi, 2020).

\section{Affective State}

Affective state refers to the emotions employees experience during and following emotional labor (Scott \& Barnes, 2011). Employees' affective state is contingent on the emotional labor strategy they use (Scott $\&$ Barnes, 2011). This actual state is highly relevant to employees' job-related well-being and organizational effectiveness as positive emotions are positively associated with job satisfaction and organizational citizenship behavior (extra work behavior) while negative emotions relate to less job satisfaction and more counterproductive work behavior (for reviews, Judge, 8 Kammeyer-Mueller, 2008; Shockley, Ispas, Rossi, \& Levine, 2012; Thoresen, Kaplan, Barsky, Warren, \& De Chermont, 2003).

Surface acting does not help diminishing employees' negative feelings, and the unresolved negative feelings can exacerbate (Scott \& Barnes, 2011). In contrast, deep acting can modify employees' emotional state and increase positive feelings (Scott $\&$ Barnes, 2011). While past studies consistently showed that surface acting is related to higher negative affect, they reported inconsistent findings on the link between deep acting and employees' affective state (Judge et al., 2009; Semmer, Messerli, \& Tschan, 2016; Scott \& Barnes, 2011). For example, in Judge and colleagues' study (2009), on days when employees reported a high level of deep acting, they reported feeling less positive, but in Scott and Barnes's (2011) study, daily deep acting was related to an increase in positive affect.

\section{Self-authenticity}

Authenticity is "the unobstructed operation of one's true or core self" (Kernis \& Goldman, 2006, p. 294). At first glance, it may seem impossible to maintain self- 
authenticity while engaging in emotional labor, but it has been argued that the effect of emotional labor on self-authenticity actually depends on the emotional labor strategy (Brotheridge \& Lee, 2002). Moreover, the resulting (in)authenticity of these strategies can affect employees' well-being and performance (Brotheridge $\&$ Lee, 2002). Theory and empirical research suggest that self-authenticity is a crucial aspect of psychological health (Kernis \& Goldman, 2006, Kifer, Heller, Perunovic, \& Galinsky, 2013). Likewise, a higher sense of authenticity at work is related to improved performance (Van den Bosch \& Taris, 2014).

From a theoretical perspective, one may expect that employees' sense of authenticity suffers as surface acting changes the emotional display but not the emotional experience (Brotheridge $\&$ Lee, 2002). In contrast, deep acting should not come at the cost of experiencing inauthenticity, as employees change both their display and emotional state (Brotheridge \& Lee, 2002). Yet, empirical research revealed equivocal findings for deep acting whereas surface acting was consistently negatively related to self-authenticity (Brotheridge \& Lee, 2002; Huppertz et al., 2020). For example, while Brotheridge and Lee (2002) observed that deep acting was positively related to employees' sense of authenticity, Huppertz et al. (2020) did not find any link between deep acting and self-authenticity.

\section{Customer-perceived Authenticity}

Authenticity can also be viewed and examined from a customer's perspective (Côté et al., 2013; Wang et al., 2017). In fact, customers' perception of employee authenticity is a key determinant of customer outcomes (Lechner \& Mathmann, 2020; Paul, Hennig-Thurau, \& Groth, 2015). It is positively related to perceived service quality, customer satisfaction, loyalty, and money spent by customers (Gong, Park, \& Hyun, 2020; Grandey, Fisk, \& Steiner, 2005; Groth, Hennig-Thurau, \& Walsh, 2009; Paul et al., 2015; Seger-Guttmann \& Medler-Liraz, 2016; Wang et al., 2017).

According to the emotions as social information model (Van Kleef, 2009) and its extension to emotional labor (Côté et al., 2013; Wang et al., 2017), emotional labor reveals informational cues (e.g., facial cues and tone of voice) about employees' true feelings and intentions (Côté et al., 2013; Pugh, 2001; Wang et al., 2017). Customers attend to these informational cues, particularly the authenticity of employees' displays, to predict employees' actual intentions (e.g., Is he a reliable sales-person?; 
Côté et al., 2013; Wang et al., 2017). Authentic expressions signal that the employee is trustworthy, whereas inauthentic expressions signal that the employee looks friendly because of his jobs' demands and he might be manipulative (Wang et al., 2017).

Customers perceive employees' expressions as sincere to the extent that such expressions reflect employees' true feelings (Côté et al., 2013; Wang et al., 2017). Therefore, surface acting and deep acting should affect customers' perception of authenticity differently (Côté et al., 2013; Wang et al., 2017). Consistent with this assumption, empirical findings have shown that customers can read that expressions arising from surface acting are fake (e.g., inconsistent positive displays) leading them to question employees' sincerity (Groth et al., 2009). Likewise, customers can sense the genuine expressions stemming from deep acting where employees' expressions correspond to what they actually feel (Groth et al., 2009). The authentic expression of deep acting may also be perceived as an extra effort going beyond the job requirements (e.g., she is trying her best), which enhances the perception of employees' sincerity (Grandey et al., 2005).

\section{Rewarding Interactions with Customers}

Rewarding interactions with clients reflect the extent to which employees perceive having a satisfying relationship with their customers, which involves employees' feeling of appreciation by customers (Brotheridge \& Lee, 2002). Such interactions are promising opportunities for employees to gain new resources such as a positive mood and self-efficacy, which can counter the resource depletion effect of emotional labor (Brotheridge \& Lee, 2002; Hobfoll, 1989; Hülsheger \& Schewe, 2011; Lilius, 2012). In line with this assumption, previous research showed that employees' rewarding interactions with customers were associated with decreased emotional exhaustion, the core burnout dimension (Brotheridge \& Lee, 2002; Martínez-Iñigo, Totterdell, Alcover, \& David, 2007).

From the social interaction perspective of emotional labor (Côté, 2005), employees' rewarding interaction with customers depends on the adopted emotional labor strategy. Surface acting interferes with the development of a positive connection with customers, as they would perceive inauthentic expressions as unreliable or manipulative (Côté, 2005; Zhan et al., 2016). In contrast, deep acting can facilitate a 
satisfying interaction, as customers would reciprocate employees' authentic positive expressions with similar positive feelings (Côté, 2005; Zhan et al., 2016).

This assumption has received empirical support for surface acting (Martínez-Iñigo et al., 2007). However, interestingly, empirical findings have remained mixed for the impact of deep acting on rewarding interaction with customers. For example, Martínez-Iñigo et al., (2007) showed that deep acting enhances employees rewarding interaction with their clients. Similarly, Zhan et al., (2016) found that deep acting is positively linked to positive customer treatment at both the within and the betweenperson level. Yet, according to Huppertz et al.'s (2020) findings, deep acting was not related to rewarding interactions at the within-person level.

\section{Customer Service Appraisal}

Service quality appraisal refers to customers' appraisal of the responsiveness and efficiency of the provided service (Grandey, 2003; Barger \& Grandey, 2006; Parasuraman, Zeithaml, \& Berry, 1985). Positive appraisals enhance customers' satisfaction and loyalty (Gong et al., 2020; Grandey, 2003).

Drawing on the emotions as social information perspective (Côté et al., 2013; Wang et al., 2017), one can argue that surface acting and deep acting may produce different service appraisals. Two specific mechanisms may play a role in customers appraisals: affective reactions (i.e., catching employees' expressed emotions) and cognitive appraisals (i.e., interpreting the meaning of employees' expressions; Côté et al., 2013; Wang et al., 2017). Catching the inauthentic expressions of surface acting may trigger disappointment or anger Côté et al., 2013; Wang et al., 2017). Consequently, customers may start to feel negative, resulting in unfavorable service evaluations (Côté et al., 2013; Wang et al., 2017). Likewise, inauthentic displays may lead customers to infer that the employee is not enthusiastic or devoted to offering a quality service (Côté et al., 2013; Wang et al., 2017). In contrast, detecting the authentic expressions of deep acting may elicit positive emotions and further positive evaluations of customers (Côté et al., 2013; Wang et al., 2017). Similarly, the authenticity of employees' displays may be perceived that the employee tries to provide a high quality service by truly caring about customers' needs (Côté et al., 2013; Wang et al., 2017). Supporting these theoretical ideas, studies found that deep acting is positively associated with customer tips while surface acting increased tips 
only for extravert employees (Chi, Grandey, Diamond, Krimmel, 2011; Hülsheger et al., 2015).

\section{Roadmap: Where We Need to Go from Here?}

Our review so far showed that there are several theoretical reasons to categorize emotional labor strategies in two categories: deep acting and surface acting (Grandey, 2000). Deep acting has been theorized to be a more promising strategy than surface acting in terms of improving individual and organizational outcomes. Yet, despite the significant insights gained, our understanding of emotional labor is still limited. First, empirical investigations did not consistently show that deep acting is adaptive for well-being and performance. In fact, while empirically findings were largely consistent for surface acting, the findings on the relationships of deep acting with key proximal outcomes reviewed above were largely inconsistent. Second, there is almost no causal evidence on the consequences of deep acting. A large number of cross-sectional and experience-sampling studies have been conducted but these studies do not allow for a strong test of the possible causal impact of deep acting. Finally, the current focus on deep and surface acting may be too narrow. Employees can resort to a wide range of strategies to engage in emotional labor and the deepsurface acting dichotomy does not fully reflect the emotional labor domain.

In the following sections we elaborate on these key limitations of research on emotional labor that we believe should be tackled to deepen our understanding in this domain.

\section{Resolving Inconsistent Findings: Towards a Fine-grained Understanding of Deep acting}

Deep acting is an umbrella term covering various antecedent-focused emotion regulation strategies: perspective-taking, positive reappraisal, and attentional deployment (Grandey, 2000, Hülsheger \& Schewe, 2011). This single-construct approach is also reflected in the measurement of deep acting. Extant empirical research has mostly relied on scales with broadly-worded items, such as "I make an effort to actually feel the emotions that I need to display to others" (Brotheridge \& Lee, 2003) without tapping into specific regulation strategies. 
This is an important oversight, considering that conceptually distinct strategies used for deep acting may have different consequences for emotional labor outcomes (Hülsheger \& Schewe, 2011). The scarcity of research on the relationship between specific deep acting strategies and the reviewed proximal outcomes combined with the importance of these outcomes predicting well-being and performance raises critical questions. How do specific deep acting strategies (i.e., perspective-taking, positive reappraisal, and attentional deployment) relate to the key proximal outcomes? Do they display a different pattern of relationships with these outcomes? Answering these questions is crucial for getting a better understanding of the consequences of deep acting and it may shed light on the processes underlying the mixed evidence on deep acting outcomes observed in previous research.

\section{Experimental Studies on Deep Acting}

Although the broader emotion regulation literature outside the organization sciences is filled with experimental studies (for meta-analysis, Webb, Miles, \& Sheeran, 2012), the emotional labor literature has been slow to draw on experimental designs. There are only a few lab-based experimental studies on emotional labor (e.g., Buckner \& Mahoney, 2012; Goldberg \& Grandey, 2007), and none of these studies have manipulated emotional labor strategies. Instead, these studies examined emotional labor as a result (dependent variable) of other variables (e.g., display rules), and therefore do not speak to the possible causal impact of deep acting on employee outcomes.

Until now, we could only infer information about the possible causal impact of deep acting from longitudinal studies using cross-lagged analyses (e.g., Hülsheger, Lang, \& Maier, 2010; Philipp \& Schüpbach, 2010). Yet, these analyses only allow establishing granger causality. Moreover, longitudinal studies did not provide consistent evidence for the (granger) causal relationship between deep acting and employees' well-being. In a longitudinal study conducted by Philipp and Schüpbach, (2010) deep acting was predictive of a well-being indicator (emotional exhaustion), meaning that employees using deep acting experienced less emotional exhaustion at the next assessment. However, Hülsheger and colleagues (2010) did not observe a significant lagged effect of deep acting on another well-being indicator (strain). Therefore, there is a clear need for an experimental design to ascertain the causal effects of specific deep acting strategies on employee outcomes. Such design would allow researchers to 
study emotional labor as it occurs and without any confounds of cross-sectional design (e.g. common-method bias) and self-report measures (e.g., does it measure motivation or emotion regulation?).

Given its advantages, the lack of experimental research in the field of emotional labor is surprising. A key reason for this might be the challenge of developing appropriate manipulations for perspective-taking, positive reappraisal, and attentional deployment in a highly interactive context. Indeed, while these strategies can be easily manipulated in non-interactive contexts (for a meta-analysis, Webb et al., 2012), emotional labor context may cause additional cognitive and emotional load. In non-interactive experimental paradigms, participants typically watch emotionally arousing videos and subsequently regulate their emotions in an instructed manner (Webb et al., 2012). In such settings, it is not difficult to devote one's resources to implement the instructed emotion regulation strategy. Yet, in emotional labor contexts, participants should assist customers and comply with display rules while implementing emotion regulation instructions, and all of this at the same time. This is obviously cognitively much more complex. Moreover, emotional labor may be emotionally very challenging. Participants may perceive emotional stimuli as more personally relevant in emotional labor contexts (e.g., the customer is criticizing my performance) compared to non-interactive contexts (e.g., watching emotional pictures or videos).

The highly complex nature of the emotional labor context suggests that we cannot simply generalize experimental findings from the non-work context to the emotional labor context. Consistently, several studies found that the outcomes of emotion regulation strategies may vary depending on the context (Aldao, 2013; Shafir, Schwartz, Blechert, \& Sheppes, 2015). For example, positive reappraisal has been found to be less effective in reducing negative emotions in highly intense situations (Shafir et al., 2015). Therefore, manipulating positive reappraisal or other deep acting strategies in a customer service setting may not only be a challenge in itself but may also result in different effects compared to lab research conducted in the field of non-work related emotion regulation. 


\section{A Comprehensive Taxonomy of Emotional Labors Strategies}

As evidenced by numerous studies, the surface-deep acting dichotomy has produced valuable insights. Yet, the literature has remained largely silent about other possible strategies to engage in emotional labor, which might also be prevalent and impact key employee outcomes. In fact, first evidence is available that there are other emotional labor strategies that employees can use. Recently, researchers started to pay more attention to all strategies of the process model of emotion regulation (Gross, 1998) in the context of emotional labor (Chang \& Taxer, 2020; Taxer \& Gross, 2018; Diefendorff et al., 2008). Extending Grandey's (2000) perspective, these studies showed that situation modification/selection strategies (altering the emotional aspects of the situation) of Gross's (1998) model should also be considered as emotional labor strategies. It has been argued that service sector employees have less control over their client interactions (Grandey, 2000), but there is initial empirical evidence that they do use situation selection/modification strategies to engage in emotional labor (Diefendorff et al., 2008). For example, a service employee may pass a difficult customer to a more experienced colleague.

Moreover, recent emotion regulation studies outside the emotional labor domain have demonstrated that emotion regulation is not necessarily an intrapersonal process. Instead, it can also be interpersonal (Dixon-Gordon, Bernecker, \& Christensen, 2015; Swerdlow, \& Johnson, 2020; Williams, Morelli, Ong, \& Zaki, 2018; Zaki \& Williams, 2013). This is called intrinsic interpersonal emotion regulation and is defined as "slice of interpersonal interactions deliberately devoted to influencing one's own emotions." (Dixon-Gordon et al., 2015, p. 37; Zaki \& Williams, 2013). Applying this intrinsic interpersonal emotion regulation to emotional labor, employees may regulate their emotions through regulating their customers' emotions. For example, a customer service employee can help her customer see the situation differently or more positively (Swerdlow, \& Johnson, 2020). As the customer feels better, she also regulates her own feelings. Yet, such forms of interpersonal emotion regulation has hardly received any attention in the emotional labor literature.

Notably, although these studies suggest alternative emotional labor strategies, they may not reveal the full picture. A top-down theory-driven approach is valuable but might also constrain our understanding of emotional labor strategies because the suggested additional strategies are formulated a priori based on prior theoretical 
work (Gross, 1998; Zaki \& Williams, 2013). Employees may manage their emotions in even more ways than those described in prior theoretical frameworks. We argue that a bottom-up investigation should therefore complement the present theoretical understanding of emotional labor to capture the full array of strategies. A bottomup approach entails first documenting a wide range of emotional labor strategies via interviews and subsequently categorizing these strategies based on their similarities. This procedure is consistent with calls to use new approaches to capture the full array of emotional labor strategies (Grandey \& Gabriel, 2015; Grandey \& Melloy, 2017) and may shed new light on the emotional labor domain.

\section{Conclusion}

During the past decades, significant progress has been made in understanding the nature and consequences of emotional labor. Yet, we identified three key gaps in prior research: (a) inconsistent findings on the consequences of deep acting, (b) a lack of experimental studies to test the possible causal impact of emotional labor strategies, and (c) a lack of a comprehensive bottom-up taxonomy of emotional labor strategies. We believe that addressing these gaps will not only improve our scientific understanding of emotional labor but also offer key insights to address the individual, organizational and societal challenges of emotional labor. 


\section{References}

Aldao, A. (2013). The future of emotion regulation research: Capturing context. Perspectives on Psychological Science, 8(2), 155-172. https://doi.org/10.1177/1745691612459518

Ashforth, B. E., \& Humphrey, R. H. (1993). Emotional labor in service roles: The influence of identity. Academy of Management Review, 18(1), 88-115.

Barger, P. B., \& Grandey, A. A. (2006). Service with a smile and encounter satisfaction: Emotional contagion and appraisal mechanisms. Academy of Management Journal, 49(6), 1229-1238. https://doi.org/10.5465/amj.2006.23478695

Beal, D. J., \& Trougakos, J. P. (2013). Episodic intrapersonal emotional regulation: Or, dealing with life as it happens. In A. A. Grandey, J. M. Diefendorff, \& D. E. Rupp (Eds.), Emotional labor in the 21st century: Diverse perspectives on emotion regulation at work (pp. 31-55). New York, NY: Routledge

Beal, D. J., Trougakos, J. P., Weiss, H. M., \& Dalal, R. S. (2013). Affect spin and the emotion regulation process at work. Journal of Applied Psychology, 98, 593-605. https://doi.org/10.1037/a0032559

Beal, D. J., Trougakos, J. P., Weiss, H. M., \& Green, S. G. (2006). Episodic processes in emotional labor: Perceptions of affective delivery and regulation strategies. Journal of Applied Psychology, 91(5), 1053-1065. https://doi.org/10.1037/0021-9010.91.5.1053

Brotheridge, C. M., \& Lee, R. T. (2002). Testing a conservation of resources model of the dynamics of emotional labor. Journal of Occupational Health Psychology, 7(1), 57-67. https://doi. org/10.1037/1076-8998.7.1.57

Brotheridge, C. M., \& Lee, R. T. (2003). Development and validation of the emotional labour scale. Journal of Occupational and Organizational Psychology, 76(3), 365-379. https://doi. org/10.1348/096317903769647229

Buckner, J. E., \& Mahoney, K. T. (2012). Individual differences and emotional labor: An experiment on positive display rules. Personality and Individual Differences, 53(3), 251-256. https://doi. org/10.1016/j.paid.2012.03.028

Chau, S. L., Dahling, J. J., Levy, P. E., \& Diefendorff, J. M. (2009). A predictive study of emotional labor and turnover. Journal of Organizational Behavior, 30(8), 1151-1163. https://doi.org/10.1002/ job.617

Chang, M. L., \& Taxer, J. (2020): Teacher emotion regulation strategies in response to classroom misbehavior. Teachers and Teaching, 1-17. http://dx.doi.org/ 10.1080/13540602.2020.1740198

Chi, N. W., Grandey, A. A., Diamond, J. A., \& Krimmel, K. R. (2011). Want a tip? Service performance as a function of emotion regulation and extraversion. Journal of Applied Psychology, 96(6), 1337. http://dx.doi.org/10.1037/a0022884 
Coté, S. (2005). A social interaction model of the effects of emotion regulation on work strain. Academy of Management Review, 30(3), 509-530. https://doi.org/10.5465/amr.2005.17293692

Côté, S., Van Kleef, G. A., \& Sy, T. (2013). The social effects of emotion regulation in organizations. In A. A. Grandey, J. M. Diefendorff, \& D. E. Rupp (Eds.), Emotional labor in the 21st century: Diverse perspectives on emotion regulation at work (pp. 79-100). New York: Routledge.

Deng, H., Walter, F., Lam, C. K., \& Zhao, H. H. (2017). Spillover effects of emotional labor in customer service encounters toward coworker harming: A resource depletion perspective. Personnel Psychology, 70(2), 469-502. https://doi.org/10.1111/peps.12156

Diefendorff, J. M., Croyle, M. H., \& Gosserand, R. H. (2005). The dimensionality and antecedents of emotional labor strategies. Journal of Vocational Behavior, 66(2), 339-357. https://doi. org/10.1016/j.jvb.2004.02.001

Diefendorff, J. M., Richard, E. M., \& Yang, J. X. (2008). Linking emotion regulation strategies to affective events and negative emotions at work. Journal of Vocational Behavior, 73, $498-508$ http://dx.doi.org/10.1016/j.jvb.2008.09.006

Dixon-Gordon, K. L., Bernecker, S. L., \& Christensen, K. (2015). Recent innovations in the field of interpersonal emotion regulation. Current Opinion in Psychology, 3, 36 - 42. http://dx.doi. org/10.1016/j.copsyc .2015.02.001

Grandey, A. A. (2000). Emotion regulation in the workplace: A new way to conceptualize emotional labor. Journal of Occupational Health Psychology, 5, 95-110. http://dx.doi.org/10.1037/10768998.5.1.95

Grandey, A. A. (2003). When "the show must go on": Surface acting and deep acting as determinants of emotional exhaustion and peer-rated service delivery. Academy of Management Journal, 46(1), 86-96. https://doi.org/10.2307/30040678

Grandey, A., Diefendorff, J., \& Rupp, D. E. (Eds.). (2013). Emotional labor in the 21st century: Diverse perspectives on emotion regulation at work. Routledge.

Grandey, A. A., Fisk, G. M., \& Steiner, D. D. (2005). Must "Service With a Smile" Be Stressful? The Moderating Role of Personal Control for American and French Employees. Journal of Applied Psychology, 90(5), 893-904. https://doi.org/10.1037/0021-9010.90.5.893

Grandey, A. A., \& Gabriel, A. S. (2015). Emotional labor at a crossroads: Where do we go from here? Annual Review of Organizational Psychology and Organizational Behavior, 2, 323-349. https:// doi.org/10.1146/annurev-orgpsych-032414-111400

Grandey, A. A., \& Melloy, R. C. (2017). The state of the heart: Emotional labor as emotion regulation reviewed and revised. Journal of Occupational Health Psychology, 22(3), 407-422. https://doi. org/10.1037/ocp0000067

Goldberg, L. S., \& Grandey, A. A. (2007). Display rules versus display autonomy: Emotion regulation, 
emotional exhaustion, and task performance in a call center simulation. Journal of Occupational Health Psychology, 12(3), 301-318. https://doi.org/10.1037/1076-8998.12.3.301

Gong, T., Park, J., \& Hyun, H. (2020). Customer response toward employees' emotional labor in service industry settings. Journal of Retailing and Consumer Services, 52, 1- 11. 101899. https:// doi.org/10.1016/j.jretconser.2019.101899

Goodwin, R. E., Groth, M., \& Frenkel, S. J. (2011). Relationships between emotional labor, job performance, and turnover. Journal of Vocational Behavior, 79(2), 538-548. https://doi. org/10.1016/j.jvb.2011.03.001

Gross, J. J. (1998). Antecedent- and response-focused emotion regulation: Divergent consequences for experience, expression, and physiology. Journal of Personality and Social Psychology, 74(1), 224-237. https://doi.org/10.1037/0022-3514.74.1.224

Groth, M., Hennig-Thurau, T., \& Walsh, G. (2009). Customer reactions to emotional labor: The roles of employee acting strategies and customer detection accuracy. Academy of Management Journal, 52(5), 958-974. https://doi.org/10.5465/amj.2009.44634116

Hobfoll, S. E. (1989). Conservation of resources: a new attempt at conceptualizing stress. American Psychologist, 44(3), 513.

Hobfoll, S. E. (2002). Social and psychological resources and adaptation. Review of General Psychology, 6, 307-324. http://dx.doi.org/10.1037/ 1089-2680.6.4.307

Hobfoll, S. E. (2011). Conservation of resource caravans and engaged settings. Journal of Occupational and Organizational Psychology, 84(1), 116-122. https://doi.org/10.1111/j.20448325.2010.02016.x

Hochschild, A. R. (1983). The managed heart: Commercialization of human feeling. Berkeley, CA: University of California Press.

Hallowell, R. (1996). The relationships of customer satisfaction, customer loyalty, and profitability: an empirical study. International Journal of Service Industry Management, 7 (4), 27-42. https://doi. org/10.1108/09564239610129931

Holman, D., Martinez-iñigo, D., \& Totterdell, P. (2008). Emotional labour and employee well-being: An integrative review. In N. Ashkanasy \& C. L. Cooper (Eds.), Research companion to emotion in organizations (pp. 301-315). Northampton, MA: Edward Elgar Publishing. http://dx .doi. org/10.4337/9781848443778.00029

Hülsheger, U. R., Lang, J. W. B., \& Maier, G. W. (2010). Emotional labor, strain, and performance: Testing reciprocal relationships in a longitudinal panel study. Journal of Occupational Health Psychology, 15(4), 505-521. https://doi.org/10.1037/a0021003

Hülsheger, U. R., Lang, J. W. B., Schewe, A. F., \& Zijlstra, F. R. H. (2015). When regulating emotions at work pays off: A diary and an intervention study on emotion regulation and customer tips in 
service jobs. Journal of Applied Psychology, 100(2), 263-277. https://doi.org/10.1037/a0038229 Hülsheger, U. R., \& Schewe, A. F. (2011). On the costs and benefits of emotional labor: A metaanalysis of three decades of research. Journal of Occupational Health Psychology, 16(3), 361389. https://doi.org/10.1037/a0022876

Humphrey, R. H., Ashforth, B. E., \& Diefendorff, J. M. (2015). The bright side of emotional labor. Journal of Organizational Behavior, 36(6), 749-769. https://doi.org/10.1002/job.2019

Huppertz, A. V., Hülsheger, U. R., De Calheiros Velozo, J., \& Schreurs, B. H. (2020). Why do emotional labor strategies differentially predict exhaustion? Comparing psychological effort, authenticity, and relational mechanisms. Journal of Occupational Health Psychology, 25(3), 214-226. https:// doi.org/10.1037/ocp0000179

Judge, T. A., \& Kammeyer-Muellar, J. D. (2008). Affect, satisfaction, and performance. In N. M. Ashkanasy \& C. L. Cooper (Eds.), Research companion to emotion in organizations (pp. 136-151). Cheltenham, UK: Edward Elgar.

Judge, T. A., Woolf, E. F., \& Hurst, C. (2009). Is emotional labor more difficult for some than for others? A multi-level, experience sampling study. Personnel Psychology, 62, 57- 88. http:// dx.doi.org/10.1111/j.1744-6570.2008.01129.x

Kernis, M. H., \& Goldman, B. M. (2006). A multicomponent conceptualization of authenticity: Theory and research. Advances in Experimental Social Psychology, 38, 283-357. https://doi.org/10.1016/ S0065-2601(06)38006-9

Kifer, Y., Heller, D., Perunovic, W. Q. E., \& Galinsky, A. D. (2013). The good life of the powerful: The experience of power and authenticity enhances subjective well-being. Psychological Science, 24(3), 280-288. https://doi.org/10.1177/0956797612450891

Lechner, A. T., Mathmann, F., \& Paul, M. (2020). Frontline employees' display of fake smiles and angry faces: When and why they influence service performance. Journal of Service Research. Advance online publication. https://doi.org/10. 1177/1094670520975148

Lilius, J. M. (2012). Recovery at work: Understanding the restorative side of "depleting" client interactions. Academy of Management Review, 37(4), 569-588. https://doi.org/10.5465/ amr.2010.0458

Luo, X., \& Bhattacharya, C. B. (2006). Corporate social responsibility, customer satisfaction, and market value. Journal of Marketing, 70(4), 1-18. https://doi.org/10.1509/jmkg.70.4.001

Martínez-Iñigo, D., Totterdell, P., Alcover, C. M., \& Holman, D. (2007). Emotional labour and emotional exhaustion: Interpersonal and intrapersonal mechanisms. Work \& Stress, 21(1), 30-47. https://doi. org/10.1080/02678370701234274

Parasuraman, A., Zeithaml, V. A., \& Berry, L. L. (1985). A conceptual model of service quality and its implications for future research. Journal of Marketing, 49(4), 41-50. https://doi. 
org/10.1177/002224298504900403

Paul, M., Hennig-Thurau, T., \& Groth, M. (2015). Tightening or loosening the "iron cage"? The impact of formal and informal display controls on service customers. Journal of Business Research, 68(5), 1062-1073. https://doi.org/10.1016/j.jbusres.2014.10.008

Philipp, A., \& Schüpbach, H. (2010). Longitudinal effects of emotional labour on emotional exhaustion and dedication of teachers. Journal of Occupational Health Psychology, 15(4), 494-504. https:// doi.org/10.1037/a0021046

Pugh, S. D. (2001). Service with a smile: Emotional contagion in the service encounter. Academy of Management Journal, 44(5), 1018-1027. https://doi.org/10.5465/3069445

Rafaeli, A., \& Sutton, R. I. (1987). Expression of emotion as part of the work role. Academy of Management Review, 12, 23-37. https://doi.org/10.5465/amr.1987.4306444

Rupp, D. E., McCance, A. S., Spencer, S., \& Sonntag, K. (2008). Customer (In) justice and emotional labor: The role of perspective taking, anger, and emotional regulation. Journal of Management, 34, 903-924. https://doi.org/10.1177/0149206307309261

Sanz-Vergel, A. I., Rodríguez-Muñoz, A., Bakker, A. B., \& Demerouti, E. (2012). The daily spillover and crossover of emotional labor: Faking emotions at work and at home. Journal of Vocational Behavior, 81(2), 209-217. https://doi.org/10.1016/j.jvb.2012.07.003

Sayre, G. M., Grandey, A. A., \& Chi, N.-W. (2020). From cheery to "cheers"? Regulating emotions at work and alcohol consumption after work. Journal of Applied Psychology, 105(6), 597-618. https://doi.org/10.1037/apl0000452

Scott, B. A., \& Barnes, C. M. (2011). A multilevel field investigation of emotional labor, affect, work withdrawal, and gender. Academy of Management Journal, 54, 116 -136. http://dx.doi. org/10.5465/amj.2011.59215086

Scott, B. A., Lennard, A. C., Mitchell, R. L., \& Johnson, R. E. (2020). Emotions naturally and laboriously expressed: Antecedents, consequences, and the role of valence. Personnel Psychology, 73(4), 587-613. https://doi.org/10.1111/peps.12382

Seger-Guttmann, T., \& Medler-Liraz, H. (2016). Does emotional labor moderate customer participation and buying?. The Service Industries Journal, 36(7-8), 356-373. https://doi.org/10.10 80/02642069.2016.1219724

Semmer, N. K., Messerli, L., \& Tschan, F. (2016). Disentangling the components of surface acting in emotion work: Experiencing emotions may be as important as regulating them. Journal of Applied Social Psychology, 46(1), 46-64. https://doi.org/10.1111/jasp.12364

Shafir, R., Schwartz, N., Blechert, J., \& Sheppes, G. (2015). Emotional intensity influences preimplementation and implementation of distraction and reappraisal. Social Cognitive and Affective Neuroscience, 10(10), 1329-1337. https://doi.org/10.1093/scan/nsv022 
Shockley, K. M., Ispas, D., Rossi, M. E., \& Levine, E. L. (2012). A meta-analytic investigation of the relationship between state affect, discrete emotions, and job performance. Human Performance, 25(5), 377-411. https://doi.org/10.1080/08959285.2012.721832

Slotnick, D. (2020; June). An airline will stop flight attendants from wearing face masks after passengers complained they couldn't see their smiles. Business Insider. Retrieved from https:// www.businessinsider.nl/flight-attendants-masks-smiles-complaints-garuda-indonesia-20206? international $=$ true\& $r=$ US

Sutcliffe, K.M. and Vogus, T.J. (2003), "Organizing for resilience", in Cameron, K.S., Dutton, J.E. and Quinn, R.E. (Eds), Positive Organizational Scholarship: Foundations of a New Discipline, BerrettKoehler, San Francisco, CA, pp. 94-121.

Swerdlow, B. A., \& Johnson, S. L. (2020). The Interpersonal Regulation Interaction Scale (IRIS): A multistudy investigation of receivers' retrospective evaluations of interpersonal emotion regulation interactions. Emotion. Advance online publication. https://doi.org/10.1037/emo0000927

Taxer, J. L., \& Gross, J. J. (2018). Emotion regulation in teachers: The "why" and "how". Teaching and Teacher Education, 74, 180-189. https://doi.org/10.1016/j.tate.2018.05.008

The World Bank. (2020). Employment in services. Retrieved fromhttps://data.worldbank.org/ indicator/SL.SRV.EMPL.ZS?locations=DE-NL-BE\&year_high_desc=false

Thoresen, C. J., Kaplan, S. A., Barsky, A. P., Warren, C. R., \& de Chermont, K. (2003). The Affective Underpinnings of Job Perceptions and Attitudes: A Meta-Analytic Review and Integration. Psychological Bulletin, 129(6), 914-945. https://doi.org/10.1037/0033-2909.129.6.914

Trougakos, J. P., Beal, D. J., Cheng, B. H., Hideg, I., \& Zweig, D. (2015). Too drained to help: A resource depletion perspective on daily interpersonal citizenship behaviors. Journal of Applied Psychology, 100(1), 227-236. https://doi.org/10.1037/a0038082

Van den Bosch, R., \& Taris, T. W. (2014). Authenticity at work: Development and validation of an individual authenticity measure at work. Journal of Happiness Studies, 15(1), 1-18. https://doi. org/10.1007/s10902-013-9413-3

Van Kleef, G. A. (2009). How emotions regulate social life: The emotions as social information (EASI) model. Current directions in Psychological Science, 18(3), 184-188. https://doi.org/10.1111/ j.1467-8721.2009.01633.x

Wang, Z., Singh, S. N., Li, Y. J., Mishra, S., Ambrose, M., \& Biernat, M. (2017). Effects of employees' positive affective displays on customer loyalty intentions: An emotions-as-social-information perspective. Academy of Management Journal, 60(1), 109-129. https://doi.org/10.5465/ amj.2014.0367

Webb, T. L., Miles, E., \& Sheeran, P. (2012). Dealing with feeling: A meta-analysis of the effectiveness of strategies derived from the process model of emotion regulation. Psychological Bulletin, 
138(4), 775-808. https://doi.org/10.1037/a0027600

Williams, W. C., Morelli, S. A., Ong, D. C., \& Zaki, J. (2018). Interpersonal emotion regulation: Implications for affiliation, perceived support, relationships, and well-being. Journal of Personality and Social Psychology, 115(2), 224-254. https://doi.org/10.1037/pspi0000132

Xanthopoulou, D., Bakker, A. B., Oerlemans, W. G., \& Koszucka, M. (2018). Need for recovery after emotional labor: Differential effects of daily deep and surface acting. Journal of Organizational Behavior, 39(4), 481-494. https://doi.org/10.1002/job.2245

Zaki, J., \& Williams, W. C. (2013). Interpersonal emotion regulation. Emotion, 13(5), 803-810. https:// doi.org/10.1037/a0033839

Zhan, X., Luo, W., Ding, H., Zhu, Y. and Guo, Y. (2021), "Are employees' emotional labor strategies triggering or reducing customer incivility: a sociometer theory perspective", Journal of Service Theory and Practice, 31(3), 296-317

Zhan, Y., Wang, M., \& Shi, J. (2016). Interpersonal process of emotional labor: The role of negative and positive customer treatment. Personnel Psychology, 69(3), 525-557. https://doi.org/10.1111/ peps.12114 


\section{More than one strategy: A closer} examination of the relat onspip between deep actipg and employea ditomes

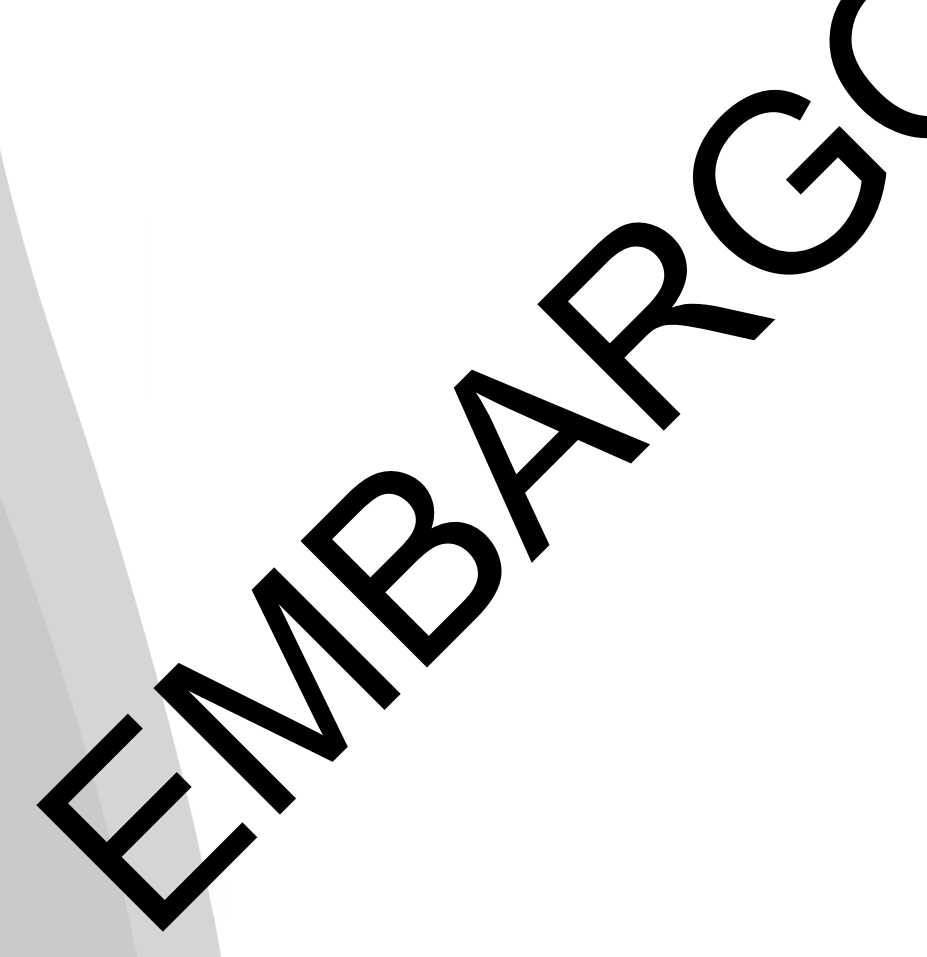

This chapter is based on: Alabak, M., Hülsheger, U. R., Zijlstra, F. R. H., \& Verduyn, P. (2020). More than one strategy: A closer examination of the relationship between deep acting and key employee outcomes. Journal of Occupational Health Psychology, 25(1), 32-45. https://doi.org/10.1037/ocp0000152 


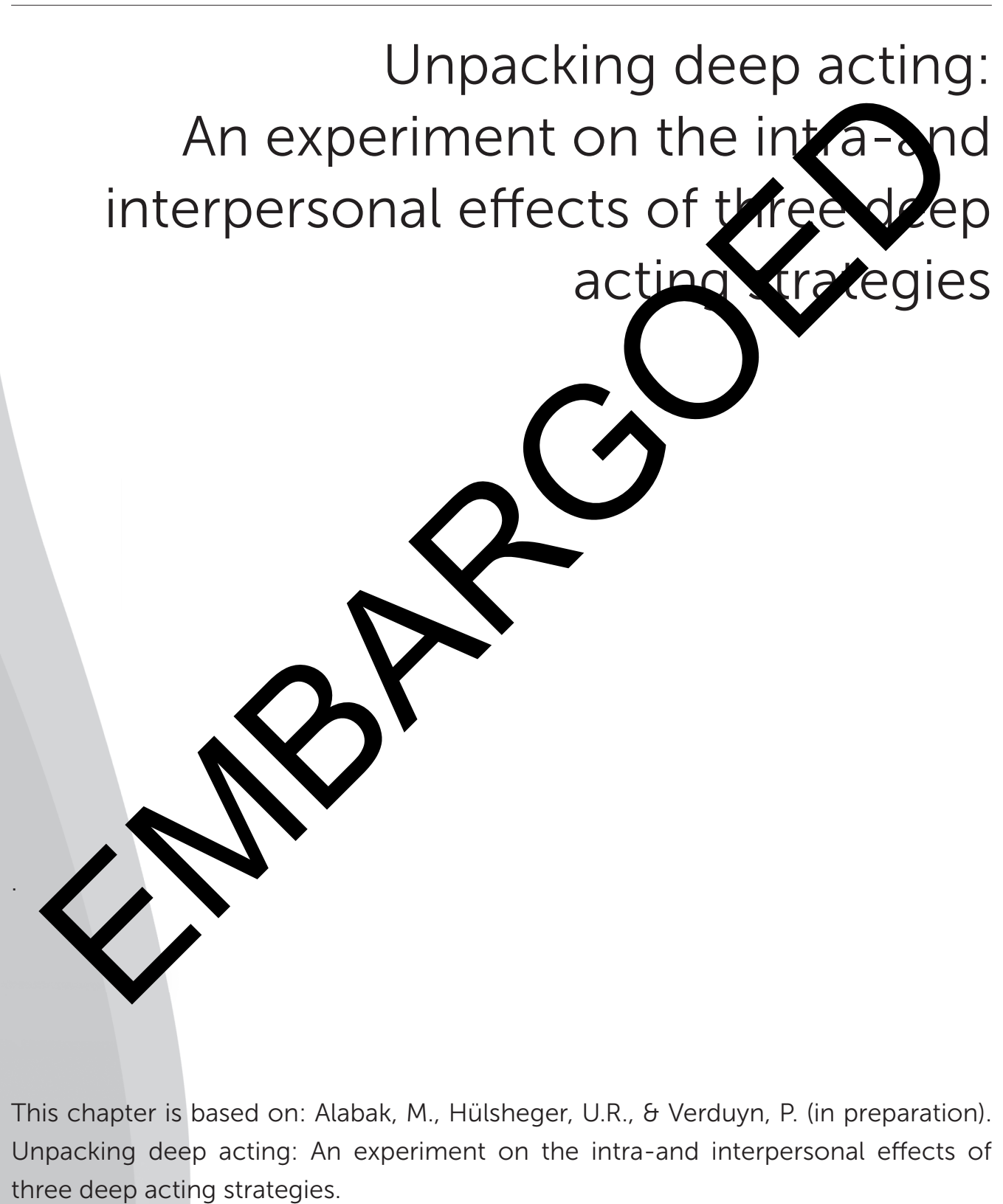




\section{CHAPTER 5}

\section{Going beyond deep and surface acting: A bott mup investigation of emotisnavor rategies}

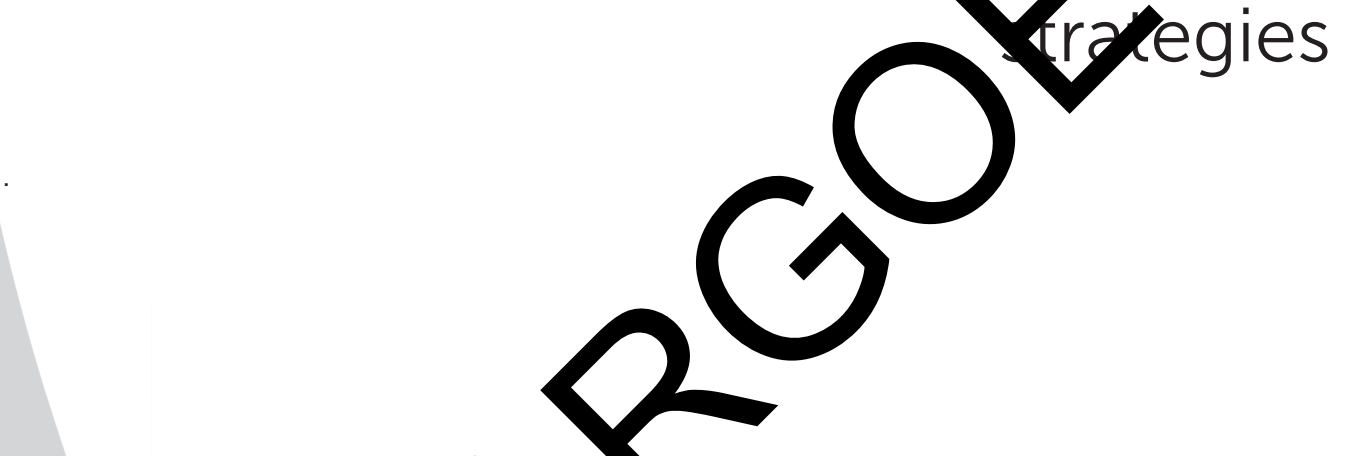

This chapter is based on: Alabak, M., Hülsheger, U.R., Schepers, J, Kalokerinos, E.K, $\&$ Verduyn, P. (under review). Going beyond deep and surface acting: A bottom-up investigation of emotional labor strategies. 
CHAPTER 6

General discussion 

Emotional labor is an inseparable part of many jobs. A large number of studies have been conducted that increased our understanding of emotional labor (for reviews, Grandey \& Gabriel, 2015; Grandey \& Melloy, 2017). However, research on emotional labor has also been characterized by empirically unsupported theories, mixed findings, and methodological limitations. As discussed in Chapter 2, we identified three important research questions that have remained unanswered: (1) Does the traditional treatment of deep acting as a unitary construct (partly) explain why mixed findings have been obtained on the relationship between deep acting and emotional labor outcomes? (2) How do specific deep acting strategies (perspective-taking, positive reappraisal, and attentional deployment) causally impact emotional labor outcomes? (3) What are other emotional labor strategies employees resort to when engaging in emotional labor besides deep and surface acting?

The primary goal of the present dissertation was to address these research questions. This final chapter is organized as follows. First, based on the findings of the three empirical chapters of this dissertation, I will discuss these three research questions that are at the core of the present dissertation. Subsequently, I will discuss an overview of the theoretical, methodological and practical contributions of the current dissertation. Finally, I will present future research opportunities that can further improve the present state of knowledge on emotional labor.

\section{Main Findings}

To address the first research question regarding the unitary or multidimensional nature of deep acting, Chapter 3 investigated the relationship between three specific deep acting strategies (perspective-taking, positive reappraisal, and attentional deployment) and three key proximal employee outcomes (resource depletion, selfauthenticity, and rewarding interactions with customers) using a daily diary approach. Our findings suggest that treating deep acting as a unitary construct is suboptimal. In line with our expectations, the three fundamentally different deep acting strategies were indeed differentially related to these key outcomes at both between and withinperson levels. Compared to the other two strategies, perspective-taking was linked to more desirable outcomes, such as higher rewarding interactions without suffering from resource depletion (observed at both levels of analysis). In contrast, positive reappraisal was found to be depleting at the within-person level. If employees use positive reappraisal more than they typically do so on a particular day, they may feel 
more depleted. Positive reappraisal was also related to less rewarding interactions at the between-person level (albeit marginally significant). Finally, attentional deployment appeared to be a non-optimal strategy. It was positively related to resource depletion at the within-person level (albeit marginally significant) and employees who frequently used attentional deployment experienced lower selfauthenticity at the between-person level.

The second research question addressed in this dissertation was: Do specific deep acting strategies causally impact key emotional labor outcomes? In Chapter 4, we conducted a customer-service simulation to compare the regulatory effect of perspective-taking, positive reappraisal and attentional deployment on resource depletion, negative affect, positive emotions, self-authenticity, perceived authenticity and service performance. Overall, our emotion regulation manipulation was not successful in creating the expected differences in the self-reported emotion regulation measures. Even though the manipulations consisted of clear instructions to use a particular strategy, participants also used other strategies (especially perspective-taking). As such, our emotion regulation manipulation may not have been sufficiently strong to override participants' habitual emotion regulation tendencies in a demanding social interaction. Participants may have resorted to their habitual emotion regulation strategies regardless of regulation instructions with the passing of time. For example, a habitual perspective-taker assigned to the attentional deployment condition, may have used attentional deployment at the start of the customer interaction but eventually resorted back to perspective taking due to regulation habits. Alternatively, the participant might have automatically used perspective-taking at the start of the interaction before recalling that he was supposed to engage in attentional deployment. Although our experimental manipulation failed, the correlational findings were still informative and again demonstrated the value of treating deep acting as a multidimensional construct. More specifically, we found that perspective-taking and positive reappraisal were associated with higher positive affect and self-authenticity and lower resource depletion. In contrast, attentional deployment was related to decreased positive affect (albeit marginally significant) without any beneficial links with other outcomes.

The third question we addressed in this dissertation was: What are additional emotional labor strategies beyond deep and surface acting? In Chapter 5, adopting 
a bottom-up approach, we first collected a broad array of emotional labor strategies and then grouped them based on their similarities. As we anticipated, we found that there are indeed more emotional labor strategies that are used by employees than previously acknowledged in the literature. These additional strategies include cognitive interpersonal (reframing customers' perspective of the situation), affective interpersonal (changing customers' undesirable feelings), solution-oriented (fixing customers' problems), waiting (adopting a wait and see approach), and avoidance (avoiding dealing with the situation) strategies.

\section{Implications}

This dissertation confirms, but also challenges, previous theorizing and research on emotional labor. Therefore, the results of the three empirical chapters contribute to the study of emotional labor in several important ways. In the following paragraphs, I will elaborate on the novel insights that can be drawn from the findings of the three empirical chapters.

\section{Theoretical Implications}

\section{A multidimensional view of deep acting}

The first main contribution of this dissertation is to demonstrate that deep acting is not a unidimensional emotional labor strategy as previous research typically assumed. Top-down (Chapter 3 and 4) and bottom-up (Chapter 5) findings provided converging evidence that deep acting is best viewed as a multidimensional construct. Specifically, findings reported in Chapter 3 and 4 clearly showed that deep acting encompasses different specific emotion regulation strategies (i.e., perspectivetaking, positive reappraisal and attentional deployment) that each have unique associations with key employee outcomes. The bottom-up taxonomy of emotional labor strategies reported in Chapter 5 further validated the multi-dimensional nature of deep acting. We found evidence that perspective-taking, positive reappraisal, and attentional deployment are used as emotional labor strategies. In addition to these strategies, we found evidence for an important yet understudied sub-strategy of deep acting: acceptance, which refers to accepting the situation as it is (Webb, Miles, \& Sheeran, 2012). However, while perspective-taking, positive reappraisal, and acceptance strategy statements were represented in separate categories, the attentional deployment strategy statements were subsumed under the avoidance 
category. This is actually not surprising given that attentional deployment is used to disengage from the situation (Sheppes \& Meiran, 2008).

This multidimensional fine-grained approach to study emotional labor is consistent with recent emotion regulation theories that have been put forth in the fundamental (non work-related) emotion regulation literature (McRae, Ciesielski, \& Gross, 2012; Uusberg, Taxer, Uusberg, \& Gross, 2019; Webb et al., 2012). For example, cognitive reappraisal, which refers to managing emotions by changing the meaning of the situation, is conceptualized a broad emotion regulation category covering specific strategies (e.g., perspective-taking, positive reappraisal, and acceptance). It has been argued that these strategies are not well represented by a uniform construct (McRae et al., 2012; Uusberg et al., 2019; Webb et al., 2012) and focusing on reappraisal as a broad category may obscure specific outcomes of different subtypes of cognitive reappraisal (McRae et al., 2012; Uusberg et al., 2019; Webb et al., 2012). Our findings support this theorizing in the work context. For instance, we found that positivereappraisal, but not perspective-taking, was related to greater resource loss in a daily diary study. It seems that taking a customer's perspective protects employees resources more than adopting a positive perspective, perhaps because of the social benefits of perspective-taking (i.e., rewarding interactions with customers).

Overall, it seems that adopting a multidimensional approach in deep acting research provides a richer understanding of the deep acting construct. When not doing so, researchers would operationalize deep acting as a unitary emotional labor strategy, which would lead to mixed conclusions about its consequences. However, by focusing on the unique impact of specific deep acting strategies, researchers can make more precise predictions about deep acting.

\section{The outcomes of deep acting}

The multidimensional view of deep acting does not only increase our understanding of the construct itself but also advances our understanding of deep acting outcomes. Prior to this dissertation, it was theoretically and empirically unclear how deep acting relates to employee and organizational outcomes. For example, the theoretical framework of emotional dissonance argues that deep acting decreases emotional dissonance by changing inner feelings, resulting in beneficial well-being outcomes (Grandey, \& Gabriel, 2015). Yet, other theoretical frameworks proposed that deep 
acting leads to both resource losses (e.g., effort) and resource gains (e.g., rewarding interactions with customers), resulting in an overall null relationship between deep acting and well-being outcomes (Brotheridge \& Lee, 2002; Grandey, \& Gabriel, 2015).

What is lacking in these theories, and what this dissertation shows, is that the relationship of deep acting with employees' well-being and performance depends on the specific deep acting strategy adopted. Specifically, perspective-taking can benefit employees in terms of well-being and potentially also performance because it appears to be not energy-consuming. Moreover, perspective taking is overall adaptive as it was found to be associated with increased positive affect, self-authenticity and rewarding interactions. These findings align with previous studies showing that perspective-taking was positively related to service employees' psychological health and customer-oriented behaviors (helping towards customers; e.g., Arnold \& Walsh, 2014; Axtell, Parker, Holman, \& Totterdell, 2007).

The results regarding positive reappraisal were more complex. In our daily diary study, we found that when employees used positive-reappraisal on a particular day more than they usually do, they experienced more resource depletion. Additionally, positive reappraisal was related to less rewarding interactions with customers at the between-person level (although this relationship was marginally significant only). Yet, in the experiment, positive reappraisal was associated with less resource depletion and higher positive affect and self-authenticity. These seemingly contradictory findings may be explained by two reasons. First, the nature of stressors might have been different across the two different contexts (real life encounters versus (ab). Deployment of reappraisal may be more taxing in the complex context of daily life because it may be more difficult to override the existing interpretations of the situation in more demanding situations (Sheppes \& Meiran, 2007, 2008; Troy, Shallcross, Brunner, Friedman, Jones, 2018). Moreover, positive reappraisal might be more likely to be associated with beneficial outcomes in the lab, as it may be less effortful in a lab context. For example, our participants might have approached their experimental task as an interesting experience or challenge, which facilitates positive reappraisal. Our experimental findings on reappraisal are indeed in line with previous experimental findings in the fundamental emotion regulation literature. Participants instructed to engage in positive reappraisal in response to stressors 
(e.g., video) experienced more positive emotions without significant mental cost (Richards \& Gross, 2000; Shiota \& Levenson, 2012). A second possible explanation for the different findings observed in our diary and lab study is that positive reappraisal may have trade-offs for employees. Even though it may help employees feel better and authentic in the short term, it may not promote beneficial outcomes when used frequently. It may come with costs in the long term, such as less rewarding interactions, which, over time, may be resource depleting. For example, when employees often use reappraisal, they may start to underestimate their customers' concerns or problems (e.g., it is not that bad, it is not a big deal), decreasing the quality of their social interactions.

Attentional deployment appears to be a suboptimal way of emotional labor. Paradoxically, although employees think about positive memories, attentional deployment may decrease their positive emotions. It showed a negative association with positive affect in the lab (although it was marginally significant). Moreover, chronic use of attentional deployment was related to decreased authenticity, a robust predictor of well-being and performance. These findings are particularly important because the potential negative impact of attentional deployment in the emotional labor context has been rarely acknowledged (e.g., Andela, Truchot, \& Borteyrou, 2015). Attentional deployment has been mostly investigated in the lab in response to non-social stimuli and has been effective in decreasing negative affect, at least in the short term (Webb et al., 2012). However, it may not be an adaptive strategy in an interpersonal setting like customer-service because it prevents continued monitoring of the social interaction, which may eventually be linked to non-favorable outcomes. Compared to other deep acting strategies (i.e., perspective-taking and positive reappraisal), it showed different relationships with our studied outcomes. It may be theoretically and practically meaningful to separate attentional deployment from the broad construct of deep acting. Our novel taxonomy in Chapter 5 may better characterize attentional deployment as an avoidance strategy, considering that employees divert their attention away from the interaction.

\section{The bottom-up taxonomy of emotional labor strategies}

The bottom-up taxonomy presented in this dissertation provides a comprehensive map of emotional labor strategies. Here, we can draw an analogy between the novel taxonomy of emotional labor strategies and a travel map. Just as a comprehensive 
travel map helps travelers explore more about new destinations, a comprehensive taxonomy of emotional labor strategies helps researchers learn more about emotional labor.

What can we learn about emotional labor from the novel bottom-up taxonomy? We identified six new, not previously examined categories of emotional labor strategies. These categories include cognitive interpersonal, affective interpersonal, solutionoriented, waiting, avoidance, and deviance in good faith strategies. When using cognitive interpersonal strategies, employees alter the way the customer evaluates the situation, which eventually regulates employees' own emotions. For example, a service employee may offer new interpretations or facts about the current problem to change the customer's perspective on it, thereby decreasing the customer's negative feelings and subsequently also his own negative emotions. As with cognitive interpersonal strategies, affective interpersonal strategies are aimed the customer. However, such strategies aim to change the customers' emotions or emotional reactions, without necessarily changing the customers' cognitions of the situation. For example, a flight attendant may draw an unsatisfied customer's attention away from the situation by offering coffee. By doing this, she can improve the customer's affect and in turn her own affect. In solution-oriented strategies, employees aim to solve the current problem, which can have regulatory effects for both client and employee. For example, a math teacher may use educational games in his class to decrease students' math anxiety and improve their enthusiasm. Such a strategy solves the underlying problem (i.e., noisy students) and makes it easier for the math teacher to stay calm. In contrast to these proactive strategies, during waiting strategies, employees remain passive and wait for the situation to end. For example, a waiter may take a deep breath without intervening in a problematic situation. Similar to waiting, during avoidance strategies, employees do not engage with the situation and even withdraw themselves from the situation. In this case, employees avoid having to deal with the present situation. For example, a teacher may end her course early when her students are not paying attention. Finally, when engaging in deviance in good faith, employees attempt to gain more control over the situation by deviating from display rules. Such deviance-like behavior is aimed at protecting oneself. For example, a service employee may inform a rude customer that he will end the interaction if the customer continues to misbehave. 
This new taxonomy can be an important starting point for further theory development in the emotional labor domain. Although current theoretical models in the emotional labor literature (e.g., Grandey, 2000) are informative to understand emotional labor strategies, they do not adequately account for the wide range of strategies used by employees. Indeed, our bottom-up taxonomy resulted in the identification of previously unrecognized emotional labor strategies in addition to commonly-studied strategies.

Broadening the scope of emotional labor research may aid in addressing the individual and organizational challenges of emotional labor. In fact, an important aim of many recent emotion regulation interventions in the non work-related emotion regulation literature is to improve interpersonal skills such as problemsolving and interpersonal reappraisal to improve well-being (e.g., Arbel, Khouri, Sagi, \& Cohen, 2020; Doré, Morris, Burr, Picard, \& Ochsner, 2017). For example, a very recent intervention study of Arbel and colleagues (2020) found that individuals who were trained in interpersonal reappraisal (i.e., helping others engage in reappraisal to decrease Covid-19 related worries) but not individuals who were trained in selfreappraisal (i.e., using reappraisal to decrease one's own Covid-19 related worries) showed a decrease in Covid-19 related worries. It may be that interpersonal emotion regulation provides opportunities for emotion regulation practice and enhance one's own emotion regulation skills (Alber et al., 2020). Thus, it can be easier than self-reappraisal (Alber et al., 2020). This favorable outcome of interpersonal emotion regulation is consistent with the resource-based perspective of emotional labor (Brotheridge \& Lee, 2002). Rewarding interactions with others (i.e., clients) can generate new resources and boost well-being (Brotheridge $\&$ Lee, 2002; Hobfoll, 1989). Therefore, our new taxonomy can be a basis of similar intervention attempts in the context of emotional labor as it revealed that employees engage in interpersonal emotion regulation strategies (e.g., cognitive interpersonal, solutionoriented) to deal with emotional labor demands.

\section{Methodological Implications}

A fine-grained assessment of emotional labor strategies

Chapter 3 and 4 made explicit that a unidimensional measure of deep acting is not ideal for studying deep acting. Previous research has predominantly used a unidimensional 
scale (Brotheridge $\&$ Lee, 2003) to measure deep acting, resulting in mixed findings. This dissertation recommends measuring specific emotion regulation strategies rather than broad strategy categories. Possible confounds of the unidimensional measure would then also be less likely. For example, when reporting deep acting use with broadly worded items (e.g., "I try to actually experience the emotions that I must show"; Brotheridge \& Lee, 2003), employees may refer to their motivation to feel the necessary emotion rather than a particular strategy they use (Grandey \& Gabriel, 2015). Thus, using a fine-grained measure, researchers can develop more nuanced predictions about deep acting and test them. For example, deep acting is likely to be linked with rewarding interactions with customers if it involves perspective-taking. This hypothesis would not be apparent and testable without a multidimensional measure of deep acting.

The bottom-up taxonomy reported in Chapter 5 is also important to obtain a better measurement of emotional labor. Existing emotional labor measures do not capture a wide array of emotional labor strategies that go beyond deep and surface acting. The bottom-up taxonomy provides a framework to develop a more comprehensive measure of emotional labor strategies. Such a measure is essential to gain a more comprehensive understanding of emotional labor.

\section{Manipulating emotional labor strategies}

Chapter 4 reported the first experiment that manipulated perspective-taking, positive reappraisal and attentional deployment in the context of emotional labor. Moreover, it adds to the limited research investigating the effectiveness of instructed emotion regulation in an interpersonal setting. A large body of fundamental emotion regulation research examined the effect of perspective-taking, positive reappraisal, and attentional deployment in response to non-social stimuli (for meta-analyses, Augustine \& Hemenover, 2009; Webb et al., 2012). In these studies, participants were typically instructed to implement a particular strategy while watching a video clip. In contrast to standard film-viewing paradigms, only a few experiments were conducted in an interpersonal context (Butler et al., 2003; Richards, Butler, \& Gross, 2003). In this case, participants received a brief instruction on emotion regulation (i.e., positive reappraisal or suppression) before discussing upsetting topics with their partner or a stranger. However, their findings were unclear. The authors did not use manipulation checks to ensure that participants applied the assigned strategy, and they did not find 
a main effects of instructed emotion regulation strategies on individual outcomes (e.g., emotions, blood pressure).

In our experimental study, we trained participants in using particular emotion regulation strategies (perspective taking, positive reappraisal, or attentional deployment) and used reminders during the session to strengthen our instructions. However, the manipulation checks showed that experimentally manipulating emotion regulation strategies in the context of emotional labor is challenging. We did not find a significant effect of the emotion regulation manipulations on the self-reported emotion regulation measures. Instead, we found a similar pattern of emotion regulation across the three conditions, with perspective-taking being most often used and attentional deployment being the least often used strategy.

What can researchers learn from these results? First, the highly interactive nature of emotional labor is not particularly compatible with non-interactive paradigms that have been typically used in emotion regulation research. Emotional labor creates additional cognitive burdens for participants. They have to perform a work-related task while being involved in dynamic social interactions and managing their emotions. Moreover, emotional labor typically involves positive display rules, which requires continued monitoring. In such a context, following emotion regulation instructions may be more complex than in (typically non-social) experimental settings used in the fundamental emotion literature.

Second, to overcome these challenges, researchers may consider improving participants' expertise in the use of emotion regulation strategies with more intense training. With repeated practice, the three deep acting strategies may become more natural, which may override participants' habitual reactions to emotional stimuli. In fact, studies conducted in non-work settings have shown that individuals get more proficient in using perspective-taking, positive reappraisal, and attentional deployment with longer sessions of training (e.g., Denny \& Ochsner, 2014; Volkaert, Wante, Van Beveren, Vervoort, \& Braet, 2020). As a certain emotion regulation strategy becomes more automatic, it can also be more accessible during client interactions (Hülsheger, Lang, Schewe, \& Zijlstra, 2015; Totterdell \& Parkinson, 1999). 


\section{Practical Implications}

Novel insights from this dissertation should not simply motivate more research on emotional labor, but also encourage new applied practices. By focusing predominantly on deep and surface acting, previous studies have potentially overlooked important practical implications of emotional labor. The current findings suggest that there are many strategies to manage one's emotions in client interactions. Based on this wider repertoire, practitioners should integrate (a range of) adaptive strategies into selection, training and intervention programs about emotional labor. For example, individuals differ in their tendency to use both intrapersonal (John \& Gross, 2007) and interpersonal emotion regulation strategies (Williams, Morelli, Ong, \& Zaki, 2018). Based on our findings, habitual perspective-takers may be preferred for jobs with high emotional labor demands. Similarly, employees with high intrinsic interpersonal tendencies may be a better fit for emotionally demanding jobs (e.g., health care) because both employees and customers can benefit from these strategies. According to Williams and colleagues' (2018) study, the more individuals use intrinsic interpersonal strategies, the more likely they are to be prosocial towards others.

Critically, when designing training or interventions, practitioners should be conscious of the multidimensional nature of deep acting. Informed by previous research, they might have overlooked that different subtypes of deep acting may lead to different outcomes. Given the positive consequences of perspective taking, its engagement should be encouraged. It is also important that these programs minimize attentional deployment and other potential maladaptive strategies (e.g., avoidance). There is already empirical evidence in the fundamental emotion regulation literature showing that avoidance is detrimental to psychological health (e.g., De Castella, Platow, Tamir, \& Gross, 2018). Attentional deployment and avoidance strategies may also prevent employees from learning from negative encounters with their clients. Practitioners therefore, may design mindfulness-based training to help employees better focus on the present interaction (e.g., Hülsheger, Alberts, Feinholdt, \& Lang, 2013). For example, Hülsheger and colleagues (2013) found that a two-week mindfulness intervention decreased employees' surface acting and emotional exhaustion. Likewise, mindfulness-based interventions may reduce the usage of other maladaptive emotional labor strategies. 


\section{Limitations and Future Directions}

The main focus of this dissertation was to increase our understanding of emotional labor. In what follows, I will consider some possible limitations of the current research and discuss future research directions.

\section{Validating the bottom-up taxonomy}

This dissertation showed that emotional labor is more than deep acting and surface acting. Future research is necessary to develop a comprehensive scale that measures and validates the novel emotional labor strategies identified in the present dissertation. Using such a novel measure, researchers can shed more light on the nature, frequency, antecedents and consequences of these strategies.

The nature of the novel strategies may encourage researchers to go beyond selfratings only. Intrapersonal emotional labor strategies are assessed by self-report measures because it is difficult to truly capture the internal regulation process with observation. However, all new additions (cognitive interpersonal, affective interpersonal, solution-oriented, deviance in good faith, waiting and avoidance) can be easily noticed by customers. Obtaining customer-ratings of these strategies may reveal more about the interpersonal nature of emotional labor.

\section{Polyregulation}

One aspect of emotional labor that we have not addressed in this dissertation and that may be important to move the field forward is polyregulation. It refers to "adopting multiple regulation strategies within a given episode" (Ford, Gross, \& Gruber, 2019; p. 198). There is a growing recognition in the emotional labor and emotion regulation literature that individuals may deploy multiple strategies to regulate their emotions in a single episode (Diefendorff, Gabriel, Nolan, \& Yang, 2019; Gabriel \& Diefendorff, 2015).

Future research can embrace this polyregulation perspective to better understand emotional labor. When do employees use multiple emotional labor strategies? Do they use strategies in sequence, simultaneously or flexibly? And, how does polyregulation affect employees' health and performance over time? For example, affective-interpersonal strategies may be initially used to decrease customer's negative feelings, so that cognitive interpersonal strategies can be more successful. 
Given the very dynamic nature of emotional labor, contextual factors should be taken into account when examining polyregulation in the emotional labor context, such as customers' reactions and the duration of the interaction. Future theorizing may combine polyregulation with the resource-based perspective of emotional labor (Brotheridge \& Lee 2002). Likewise, empirical research should examine whether polyregulation is more depleting than using a single strategy. It is also possible that adopting more strategies help employees regain resources.

\section{More experiments}

The literature is sparse on causal evidence on the link between emotional labor strategies and employee outcomes. Although our experiment reported in Chapter 4 was an important step in the direction of testing the causal effects of specific deep acting strategies, we could not establish cause and effect. Due to the failed experimental manipulation, the observed relationships remained correlational in nature, and strong claims about the impact of deep acting strategies on employee outcomes cannot be made.

Our experimental study showed that testing the impact of emotional labor strategies in the lab may require more sophisticated paradigms than used in the fundamental emotion regulation literature. Researchers should consider how to strengthen the impact of emotion regulation manipulations in the context of emotional labor settings. For example, participants' expertise in the use of emotion regulation strategies may be improved using extensive training. They can be first trained with non-interactive stimuli (e.g., video) and then with scenarios. We used scenarios and a trial call for emotion regulation practice. It may be more effective to precede this by a training with non-social stimuli. Participants may gain more confidence in the use of a particular strategy, as it may be easier to first implement that strategy without having to interact with another person. There is also value in collecting continuous ratings (Gabriel \& Diefendorff, 2015) to observe the dynamic nature of emotional labor.

In future research, it is also necessary to conduct high-powered studies. Our experiment in Chapter 4 lacked the power to observe the expected impacts of manipulated deep acting strategies on outcomes. In future studies with more participants, researchers may consider applying our training materials in multiple 
training sessions to test the effects of specific deep acting strategies e.g., Denny, \& Ochsner, 2014; Hülsheger, Lang, Schewe, \& Zijlstra, 2015).

\section{Conclusion}

The present dissertation constitutes a critical step to further advance the study of emotional labor both theoretically and methodologically. I began with a literature review that shows that past emotional labor research is limited in three respects: a lack of understanding of (a) the nature and consequences of deep acting, (b) the causal impact of deep acting strategies, and (c) emotional labor strategies that go beyond deep and surface acting. Three empirical studies were conducted to address these critical research gaps. First, our findings suggested that deep acting is a multidimensional construct that involves different emotion regulation strategies. Treating it as a unitary construct may mask the unique impacts of underlying strategies, resulting in mixed findings on employee outcomes. Second, our findings revealed the challenges associated with experimental manipulation of emotional labor strategies. Finally, this dissertation advanced the emotional labor literature by going beyond the traditional focus on deep acting-surface acting and by revealing new strategy categories, each of which might have a unique impact on employee and organizational outcomes. 


\section{References}

Andela, M., Truchot, D., \& Borteyrou, X. (2015). Emotional labour and burnout: Some methodological considerations and refinements. Canadian Journal of Behavioural Science, 47, 321-332. http:// dx.doi.org/10.1037/cbs0000024

Arbel, R., Khouri, M., Sagi, J., \& Cohen, N. (2020). Reappraising Others' Negative Emotions as a way to Enhance Coping during the COVID-19 Outbreak. (Unpublished manuscript).

Arnold, K. A., \& Walsh, M. M. (2015). Customer incivility and employee well-being: Testing the moderating effects of meaning, perspective taking and transformational leadership. Work $\&$ Stress, 29(4), 362-378. https://doi.org/10.1080/02678373.2015.1075234

Augustine, A. A., \& Hemenover, S. H. (2009). On the relative effectiveness of affect regulation strategies: A meta-analysis. Cognition and Emotion, 23(6), 1181-1220. https://doi. org/10.1080/02699930802396556

Axtell, C. M., Parker, S. K., Holman, D., \& Totterdell, P. (2007). Enhancing customer service: Perspective taking in a call centre. European Journal of Work and Organizational Psychology, 16(2), 141-168. https://doi.org/10.1080/13594320600989583

Brotheridge, C. M., \& Lee, R. T. (2002). Testing a conservation of resources model of the dynamics of emotional labor. Journal of Occupational Health Psychology, 7(1), 57-67. https://doi. org/10.1037/1076-8998.7.1.57

Brotheridge, C. M., \& Lee, R. T. (2003). Development and validation of the emotional labour scale. Journal of Occupational and Organizational Psychology, 76(3), 365-379. https://doi. org/10.1348/096317903769647229

Butler, E. A., Egloff, B., Wlhelm, F. H., Smith, N. C., Erickson, E. A., \& Gross, J. J. (2003). The social consequences of expressive suppression. Emotion, 3(1), 48-67. https://doi.org/10.1037/15283542.3.1.48

De Castella, K., Platow, M. J., Tamir, M., \& Gross, J. J. (2018). Beliefs about emotion: implications for avoidance-based emotion regulation and psychological health. Cognition and Emotion, 32(4), 773-795.

Denny, B. T., \& Ochsner, K. N. (2014). Behavioral effects of longitudinal training in cognitive reappraisal. Emotion, 14(2), 425-433. https://doi.org/10.1037/a0035276

Doré, B. P., Morris, R. R., Burr, D. A., Picard, R. W., \& Ochsner, K. N. (2017). Helping others regulate emotion predicts increased regulation of one's own emotions and decreased symptoms of depression. Personality and Social Psychology Bulletin, 43(5), 729-739. https://doi. org/10.1177/0146167217695558

Ford, B. Q., Gross, J. J., \& Gruber, J. (2019). Broadening our field of view: The role of emotion 
polyregulation. Emotion Review, 11(3), 197-208. https://doi.org/10.1177/1754073919850314

Gabriel, A. S., \& Diefendorff, J. M. (2015). Emotional labor dynamics: A momentary approach. Academy of Management Journal, 58(6), 1804-1825. https://doi.org/10.5465/amj.2013.1135

Grandey, A. A. (2000). Emotion regulation in the workplace: A new way to conceptualize emotional labor. Journal of Occupational Health Psychology, 5, 95-110. http://dx.doi.org/10.1037/10768998.5.1.95

Grandey, A. A., \& Gabriel, A. S. (2015). Emotional labor at a crossroads: Where do we go from here? Annual Review of Organizational Psychology and Organizational Behavior, 2, 323-349. https:// doi.org/10.1146/annurev-orgpsych-032414-111400

Grandey, A. A., \& Melloy, R. C. (2017). The state of the heart: Emotional labor as emotion regulation reviewed and revised. Journal of Occupational Health Psychology, 22(3), 407-422. https://doi. org/10.1037/ocp0000067

Hobfoll, S. E. (1989). Conservation of resources: a new attempt at conceptualizing stress. American Psychologist, 44(3), 513.

Hülsheger, U. R., Alberts, H. J. E. M., Feinholdt, A., \& Lang, J. W. B. (2013). Benefits of mindfulness at work: The role of mindfulness in emotion regulation, emotional exhaustion, and job satisfaction. Journal of Applied Psychology, 98(2), 310-325. https://doi.org/10.1037/a0031313

Hülsheger, U. R., Lang, J. W. B., Schewe, A. F., \& Zijlstra, F. R. H. (2015). When regulating emotions at work pays off: A diary and an intervention study on emotion regulation and customer tips in service jobs. Journal of Applied Psychology, 100(2), 263-277. https://doi.org/10.1037/a0038229

John, O. P., \& Gross, J. J. (2007). Individual differences in emotion regulation. In J. J. Gross (Ed.), Handbook of emotion regulation (pp. 351-372). New York, NY: Guilford Press

McRae, K., Ciesielski, B., \& Gross, J. J. (2012). Unpacking cognitive reappraisal: Goals, tactics, and outcomes. Emotion, 12(2), 250-255. https://doi.org/10.1037/a0026351

Richards, J. M., Butler, E. A., \& Gross, J. J. (2003). Emotion regulation in romantic relationships: The cognitive consequences of concealing feelings. Journal of Social and Personal Relationships, 20(5), 599-620.

Richards, J. M., \& Gross, J. J. (2000). Emotion regulation and memory: The cognitive costs of keeping one's cool. Journal of Personality and Social Psychology, 79(3), 410-424. https://doi. org/10.1037/0022-3514.79.3.410

Sheppes, G., \& Meiran, N. (2008). Divergent cognitive costs for online forms of reappraisal and distraction. Emotion, 8(6), 870-874. https://doi.org/10.1037/a0013711

Uusberg, A., Taxer, J. L., Yih, J., Uusberg, H., \& Gross, J. J. (2019). Reappraising reappraisal. Emotion Review, 11(4), 267-282. https://doi.org/10.1177/1754073919862617

Totterdell, P., \& Parkinson, B. (1999). Use and effectiveness of self-regulation strategies for improving 
mood in a group of trainee teachers. Journal of Occupational Health Psychology, 4(3), 219-232. https://doi.org/10.1037/1076-8998.4.3.219

Troy, A. S., Shallcross, A. J., Brunner, A., Friedman, R., \& Jones, M. C. (2018). Cognitive reappraisal and acceptance: Effects on emotion, physiology, and perceived cognitive costs. Emotion, 18(1), 5874. https://doi.org/10.1037/emo0000371

Volkaert, B., Wante, L., Van Beveren, M. L., Vervoort, L., \& Braet, C. (2020). Training adaptive emotion regulation skills in early adolescents: the effects of distraction, acceptance, cognitive reappraisal, and problem solving. Cognitive Therapy and Research, 44, 678-696. https://doi.org/10.1007/ s10608-019-10073-4

Webb, T. L., Miles, E., \& Sheeran, P. (2012). Dealing with feeling: A meta-analysis of the effectiveness of strategies derived from the process model of emotion regulation. Psychological Bulletin, 138(4), 775-808. https://doi.org/10.1037/a0027600

Williams, W. C., Morelli, S. A., Ong, D. C., \& Zaki, J. (2018). Interpersonal emotion regulation: Implications for affiliation, perceived support, relationships, and well-being. Journal of Personality and Social Psychology, 115(2), 224-254. https://doi.org/10.1037/pspi0000132 

Appendix 



\section{Summary}

With the rapid rise of service-based economies, emotional labor has been critically involved in individuals' work-life. For example, in the current Covid-19 pandemic, you might have noticed that a welcoming smile is an integral part of cashiers, baristas, or waiters' work. Although their smiles are not visible under their face masks, they regulate their emotions to express positivity towards their customers.

In the past 20 years, research on emotional labor has grown and predominantly investigated two main emotional labor strategies: surface acting (modifying only external expressions) and deep acting (modifying inner feelings). Theoretical models have been developed to describe the relationships between these strategies and employees' well-being and performance. Cross-sectional and daily diary studies have examined the underlying proxies that explain these relationships.

Yet, despite this progress, three key questions remained unexamined. 1) Why does research on the consequences of deep acting produce inconsistent findings? Is it due to ignoring its multidimensional nature? 2) How do different deep acting strategies causally relate to emotional labor outcomes? 3) What are other emotional labor strategies besides deep and surface acting?

Chapter 1 elaborates on these three questions, and how the present thesis addresses them.

Chapter 2 presents an up-to-date view of the emotional labor literature by synthesizing what is presently known in the literature and how the field can be further advanced. In this review, we particularly focus on two traditional strategies (surface acting and deep acting). Several recommendations from this review have been obtained: the need to examine a) the multidimensional nature of deep acting, b) the causal effect of specific deep acting strategies on well-being and performance indicators, c) a comprehensive taxonomy of emotional labor strategies.

Chapter 3 provides a finer-grained investigation of deep acting. We argued that considering deep acting as a uniform strategy overlooks fundamental differences among deep acting strategies (perspective-taking, positive reappraisal, and attentional 
deployment), which complicates understanding the consequences of deep acting. We predicted that three specific deep acting strategies are differently associated with proximal emotional labor outcomes (resource depletion, self-authenticity, and rewarding interactions with customers). Using a daily diary study, we supported our prediction. More specifically, compared to the two other strategies, perspectivetaking seemed to be a particularly adaptive way of deep acting. It was positively associated with rewarding interactions at both within-person and between-person levels. In contrast, positive reappraisal was negatively related to rewarding interactions with customers at the between-person level (albeit marginally significant). Positive reappraisal was also energy depleting for employees. They felt more depleted when they used positive reappraisal than they typically do so on a particular day. Similarly, attentional deployment appeared to be less adaptive than perspective-taking for employees' well-being. It was linked to more resource depletion at the within-person level (albeit marginally significant). Furthermore, employees who frequently used attentional deployment reported lower self-authenticity at the between-person level.

Building on Chapter 3, in Chapter 4, we examine the potential causal impacts of the three deep acting strategies on resource depletion, negative affect, positive emotions, self-authenticity, perceived authenticity, and service performance. We experimentally manipulated these three strategies in a travel agency simulation. However, our manipulation failed to lead to the expected differences in the engagement of emotion regulation. In particular, participants predominantly engaged in perspective-taking regardless of the experimental condition they were assigned to. Nevertheless, this chapter offers important theoretical and methodological insights. Theoretically, the correlational findings confirmed that perspective-taking, positive reappraisal, and attentional deployment are different strategies. We found that perspective-taking and positive reappraisal were related to higher positive affect and self-authenticity, while they were related to lower resource depletion. In contrast, attentional deployment was linked to less positive affect (albeit marginally significant). Methodologically, this experiment informs us that manipulating emotion regulation in the context of emotional labor may require a more sophisticated design. For example, participants may need more intense training on emotion regulation to improve their expertise in the use of emotion regulation. 
Chapter 5 argues that the current emotional labor literature is constrained to two broad emotional labor strategies. Using a bottom-up approach, we interviewed employees to collect a comprehensive list of emotional labor strategies. As expected, we found evidence for a wide range of emotional labor strategies beyond what is theoretically suggested. More specifically, we observed six novel strategy categories: cognitive interpersonal (changing the way the customer evaluates the situation), affective interpersonal (changing the customer's emotions), solution-oriented (solving the customer's problem), waiting (passively waiting for the situation to be over), avoidance (staying away from the situation) and deviance in good faith (deviating from display rules to protect one's self-esteem).

Finally, Chapter 6 discusses how these findings can advance the current theoretical, methodological, and practical understanding of emotional labor. It also acknowledges the possible limitations of the empirical studies reported in this dissertation and provides future research questions. 



\section{Bottom-up emotional labor strategies (Chapter 5) Dutch Sample}

\section{Cluster 1-Surface acting}

Wear a mask and say "Good day, how are you?"

Fake my emotions and smile

Try to think that I have to behave normally

Continue my conversation with a customer as if everything was normal

Put aside my feeling and do what is good for situation

Try to look neutral and not show that I am mad

Place my frustration aside

Do my best not to show my emotions

Do not respond emotionally

Switch off my emotions and react according to customer's behavior

Switch off my emotions

Try not to show my emotions

Approach a customer the way I am without actually having emotions because I do it every day with so many people

Stay polite but very detached

Make sure that my tone is neutral

Try to take a step back from my emotions and observe the situation to get a sense what really happened

Put aside any skepticism and negative experiences from the past

Try to keep my composure

Feel very neutral and respond neutrally

\section{Cluster 2-Being Professional}

Focus on my breathing

Stay calm because I am inherently calm

Benefit from my posture to get in my role

Put all my effort in to pay attention on what I am doing, on my mimicry and with everything

Stay true to myself and believe in my work abilities

Stay conscious on the role I find myself in and think consciously in which role I take in Maintain the business picture 
Approach a situation professionally and neutrally

Stay professional

Stay calm and professional

\section{Cluster 3-Deviance in good faith}

Indicate a client that visiting hours are over and if he/she does not leave, security will assist him/her

Tell a patient "Now you are crossing the line. We are not continuing with this."

Tell a customer that "you are being very rude to me; I am going to take a step back because I won't help you further."

Call security

Think that I do still have some self-respect that I won't allow this misbehavior

Think that "dick buy it" but do not say it

Say "Jesus, dick, stop yelling at me. God, what a dick." in my mind

Become somewhat tenser

Be not that friendly anymore

Find very difficult to control myself

My genuine emotions change automatically depending on the situation

With my uniform I tell things with an authority figure

\section{Cluster 4-Waiting}

Think that it is often about salary

Think that it is not personal but business

Think that " There is one good thing about this job. In a bit, passengers will leave this flight and I will probably never see these people again. And if I do have them onboard again, then I probably won't recognize them and they won't remember me for sure."

Remind myself that keep going it is almost the end of a day

Think that in a bit they are gone and I forget about it

Think that "okay, he will go away by himself"

Think that I am not the one causing the problem

Think that "okay never mind, just let it go"

Just let it go

Tend to stay in the background and think "Have fun!"

Take myself out of a situation and go for a walk 
Be distant from a situation

Switch my task with a colleague

Ask a colleague to take over my customer

Distance myself mentally

Finish my task as fast as possible to get rid of a customer

Count till 10

Think that "Okay, just think for a second, stay calm, just chill."

Be not solution-oriented but be closing-oriented

\section{Cluster 5-Solution-oriented}

Think that I cannot do anything about a problem anymore and try to neutralize a problem

Think that it is better to handle a situation now, then I won't have to think about it anymore

Think how I can come through the current situation

Think that how I can approach a situation constructively as possible

Think about how to solve a customer's problem

Think that the most important is to come to a good solution

Immediately address a customer problem before it escalates

Try to come up with a solution as fast as possible

Analyze a situation

Appease a situation

\section{Cluster 6-Cognitive interpersonal}

Genuinely tell a customer I am not able to give this service and mention other options Explicitly say that "I understand you are angry and frustrated, I would have the same. But I cannot do anything for you right now. The only thing I can advise you to do is to follow these steps and report your complaint with the right person." (55)

Tell a customer that "Yeah sorry, but it is the idea that we both come out of it to reach a solution"

Explain that I cannot do anything about it

Try to convince the customer by telling that "Hey sir, I am also only doing my job. Look I haven't asked for that or that. So I am just doing my job. I am trying to do it as best as I can. You are maybe not happy with the price. Yeah, but yeah, I did not make those prices. That is what it is." 
Stay honest about the customer's problem, don't beat around the bush

Be direct

Hold on to my point, be direct and don't say too much

Push customers to a certain direction

Keep arguing for my explanation but stay friendly

Create silence and ask questions

Try to stay calm and explain what the problem is

Honestly explain the reasons of a problem by showing my vulnerable side a bit

Try to calmly explain the both sides of a problem

Explain things and get mutual understanding

Try to explain why a situation occurs

Explain the cause of a situation

Try to explain why a situation is the way it is by giving examples if necessary

Explain to the student how their behavior affects others

Give an explanation about a client's problem and let him/her think about it

Explain what the problem is, what a customer did wrong, and what he/she can do better the next time

Give explicit and step by step instructions to a student

Try to listen to a student, but also try to make the student listen to me

Try to find a middle ground with a customer because I will do business with him/her later

Try to summarize like, "Is it correct this is what I heard and is this what I understand? "And then I try to reach a sort of compromise

Suggest to organize a meeting at a later date to be able to discuss my customer's problem better

Stay very factual

Discuss a situation with my colleagues to see what I can do best

\section{Cluster 7-Perspective Taking}

Respect a student's values and opinions

Be empathetic of a customer's situation and act accordingly

Try to empathize

See a customer as a person who has emotions

Put myself in a customer's shoes

Understand how a customer feels 
Try to understand a customer's view

Understand that it is a difficult situation for a customer Understand that a client is sick and he/she has worries

Remind myself not to treat others in a way I don't want to be treated

Think that "yeah the customer is probably really busy"

Stay friendly and think that this is the first time, and for a student it is all scary

Think that a customer is not evil, so I have to maintain my calmness

Adjust my breathing and slow down my words to feel calm

Ask myself "How bad is it actually what he is doing? It is not that bad because it is going well. And even if it was not going well, how bad is it? Not that bad."

Switch my emotions to match up with a customer's emotion

\section{Cluster 8-Being Positive}

Genuinely be friendly

Be automatically friendly

Find it easy to stay friendly

My interaction with a customer unconsciously goes well

Keep smiling

Be friendly and polite

Act friendly

Look friendly

Stay very polite

Try to stay friendly

Stay polite

Stay friendly

Stay positive because I want to be fair for everyone

Try to keep smiling because I think a smile can usually have de-escalating effects

Act as a patient nurse

Talk to a client as if he/she was a kind client

Look at a student in a friendly way

Be extra friendly and try to make extra eye contact

Stay calm

Thank for feedback and go on 


\section{Cluster 9-Affective interpersonal}

Create a bit of bond with the customer by showing empathy to convince the customer what I want to do

Be concerned with making the customer feel comfortable

Fulfill customers' wishes to keep them as happy as possible

Try to keep the customer as calm as possible

Try to fulfill the client's concern

Use humour

Make jokes to keep an atmosphere fun

Make jokes to make things positive

Try to make the customer feel loved and welcomed because he/she is in a pitiable situation

Put my arm around the customer or take his/her hands

Call the patient by his/her first name to be approachable

Turkish sample

\section{Cluster 1-Cognitive Interpersonal}

Tell a customer that "Sorry, there is nothing I can do, this is not allowed" because his/ her request is against the company rules."

Try to calmly explain the reasons of why a customer's request is unreasonable

Calmly explain why the customer is not right

Try to explain why I am performing a particular task in a nice way

Try to explain the reason of my slow service

Try to find other ways to explain the company rules that seem unreasonable to the customer to comfort him/her

Explain why the customer has to wait

Calmly explain that the mistake is not related to my company

Guide the customer with correct questions

Attempt to explain what I think about the situation to avoid misunderstanding in the situation

Explain the issue with simpler examples so students can understand

Ask the customer to empathize with me by asking questions "If I requested the same thing how would you react? ; How would you feel if I made this request?"

Push a customer to empathize with me by saying "Please put yourself in my shoes, what would you feel? I should be fair towards each customer about product 
exchange. I am happy to assist you to choose another dress for you."

Ask the customer to put him/herself to my shoes by saying "Would you make such a decision if you were me?"

Create awareness of the uncooperative attitude and behavior of the customer towards me by explaining things from my perspective

Try to make myself understood by the customer

Let a customer knows that I cannot perform my job properly under his/her pressure Show a customer that the current argumentation is pointless by saying "if we continue to argue, I cannot serve other customers. As you see, they are waiting to be served and we are wasting their time. We disrespect other customers."

Try to convince a customer that his/her claims are not correct

Tell the customer his/her expectation is not realistic

Explain the customer why he/she should wait while saying bad things about him/her in my mind

Tell a customer "if you do not like your hair, you can try other hair dressers next time" Ask annoying customers to leave the restaurant because I think that if they don't leave I might lose other customers, and that I need to think of the restaurant's reputation

\section{Cluster 2-Solution-oriented}

Try to find a compromise with the customer even it takes hours

Suggest a solution for the benefit of both me and a customer

Propose a quick compromise to solve the problem

Devote my energy to fixing a customer problem because if I sincerely help the customer, he/she becomes kind to me in return

Be solution-oriented

Focus on possible solutions

Change the subject of the conversation, as a result there is no problem anymore

Try to divert the customer's attention to the main problem

Try to divert the customer's attention from negative things to positive things in the project

Pass the customer to my more experienced colleague

Double check my answer with my colleague

Put on background music

Direct my attention to a task which makes me feel successful at my job 


\section{Cluster 3-Affective Interpersonal}

Show affection

Try to sound and look as enthusiastic as possible

Be friendly and respectful

Be sympathetic and friendly

Try to be warm and friendly

Be customer oriented

Focus on saving my relationship with the customer by making the customer feel he/ she is important for us

Focus on how to make a customer satisfied

Try to make the customer to feel more positive

Offer free meal, dessert or drink to decrease the customer's negative emotions

Try to eliminate the customer's frustration

Lie to the customer to comfort his/her

Flatter the customer

Make a customer feel right about the situation because I think customers get pleasure to feel superior than waiters

Try make the customer feel right by apologizing

Try to analyze the customer's personality based on his/her reactions and then behave accordingly

Analyze the customer's personality and tell him/her what he/she wants to hear

Relate to customers so that they see me as a friend/sister

Get the customer to sympathize with me

\section{Cluster 4-Perspective taking}

Do not take the patient's anger personally because I know that she goes through a difficult process

Be aware that everyone does not see the same thing

Be aware of the fact that a customer sees the situation different than I see

Think that if I were a customer, I might think similarly

Try to empathize with the customer

Try to understand what a customer thinks and wants

Put myself on the customer's shoes

Think about the possible reasons of a customer attitude, and then behave accordingly

Think about why a customer does a particular behavior 
Think that a customer may have different understanding and standards than mine

Think that these naughty and loud behaviors are normal in that age group; I was like them when I was a kid

Think that "the reasons of students' poor performance might be that math is a difficult subject, and all students are not good at maths rather than they are lazy"

See my students as my kids

Imagine customer as a baby who has no knowledge about products

\section{Cluster 5-Positive reappraisal}

Think that I need to protect my mood

Give myself self-encouragement by telling inside I am good at my job

Tell myself that I will handle this issue just like I did before

Think that I will take a break after the current interaction

Think that come on! Why am I getting annoyed by such a stupid customer?

Tell myself "be patient, the day will almost end"

Think that I did what I have to do; so I should not worry more

Attribute the customer's rudeness to his/her unhappiness in life rather than my performance

Think that the customer just wants to vent his/her anger

Think that the customer looks for someone in a lower status to vent his/her frustration on

Think that I am not the reason for the customer's frustration; he/she is the reason his/ her frustration

Think that the customer is indeed disappointed with my company regulations; not with me

Think that I am not the only one who is responsible of the situation

Think that the customer does not have to like everything

Think that I cannot make every customer satisfied

Think that people have more terrible problems than my problem with the customer

\section{Cluster 6-Acceptance}

Accept the situation as it is

Accept difficult encounters as part of my job

See customer problems as part of my job

See customer as money 
Think that if my customers are not happy with me, I cannot make money

Think that if a customer likes my service, I can make more money

Think that "I work to make money; if I earn the customer's trust, I could make more money."

Think that I will earn money if I convince the customer to buy the product

Think that being polite always leads to better outcomes than being aggressive and internalize this thought

Be patient as patience brings good things

Think that my potential negative reaction will get worse treatment in return

Think that if I relieve my true feelings, I will regret it later

Think that I should not make the students understand my sadness as they may get sad

Be aware that if I approach a negative customer negatively, I exacerbate the problem

Think that if I say bad things right now, the student may lose her interest in my course

Think that how I can make my job better

Sincerely think about how I can apply the customer's feedback to my job

Consider each passenger as a person who is flying in my company airplane for the first time and try to ensure that the customer will choose my company again

Plan in my mind the next steps as the customer was talking

Think that indeed, the customer is right

Think about how I can make the customer less angry

Think that I need to be agreeable otherwise I may lose my job

Think that this is my duty; therefore I have to do it

Think that this is my job; I need to show one last effort

\section{Cluster 7-Deviance in bad faith}

Make eye contact and waited a little bit to see whether the student realizes his/her misbehavior

Show with my facial expression that I do not approve the student's behavior

Slightly raise my voice to show that I get angry at a student's behavior

Let the customer see that I feel offended

Be aloof towards the customer

Take things personally and could not control my emotions

Serve without smiling and perform my job at a minimum level

Not try to be so friendly 
Be not friendly with the customer

Be not friendly, stop smiling and do not laugh at customer's jokes

Laugh ironically and lightly

Provide my service scornfully

Shake a customer's coke just before serving it to take revenge

\section{Cluster 8-Surface acting}

Try to look not angry

Look strong and not reflect my negative mood

Hide that I am annoyed

Do not show that I am annoyed

Try to not vent my emotions

Control my emotions

Think that I should not show my anger

A little bit suppress my anger

Suppress my anger

Show neutral facial expressions

Serve with a neutral face while hiding my true feelings

Try to have a poker face

Try to look calm while saying bad words inside my head

Swear at the customer in my mind but smile at him/her

Wear my mask and try to be friendly

Only laugh, I do not show my genuine thoughts

Disconnect with my emotions and focus on only my task

Be aware that my emotions do not improve my performance; instead, they weaken my performance so I put my emotions away

Think that the customer is not my friend; I need to be professional. I cannot reveal my true feelings

Try to look professional because I care about my reputation at work

Be serious and modest

Keep in my anger

\section{Cluster 9-Waiting}

Stay calm

Try to keep calm 
Try to stay calm as much as possible

Pray the God for help (in my head)

Say a very short pray in my head

Breathe deeply and think that this is my job; I have to serve the customer

Count to 20

Take a deep breath

\section{Cluster 10-Avoidance}

Stay away from the situation and take a 10-minute break

Divert my attention away from the situation

Walk away from the interaction and approach other customers

Stay away from the situation

Calm down without feeling a need to do something to stay calm

Without doing anything my negative emotions go away

Do not mind the situation

I did not do or think anything

Pretend like nothing happened after the customer complained about me

Try to ignore the customer's annoying attitude

Let it go because the customer will not get my point

Think that "Never mind, I am wasting my time"

Think that the customer will not understand me; I should do my job quickly to get rid of him 



\section{Impact paragraph}

Successfully managing one's emotions at work should help maintain well-being and social functioning (Grandey \& Gabriel, 2015). Given this evident importance of emotion regulation, I will discuss how the findings of the current dissertation can benefit science and society in this paragraph. In particular, I will focus on two points: 1) shifting from broad categories to specific emotion regulation categories, 2) considering a broad range of strategies.

The first key message that can be taken from this dissertation is that researchers and practitioners should focus on specific emotional labor strategies rather than broad categories. Failing to do so may lead to an incomplete understanding of emotional labor. To date, research on emotional labor has mainly studied two broad categories. In particular, theoretical and practical recommendations regarding deep acting have remained limited. This dissertation showed that differentiating specific strategies under the broad category of deep acting can provide richer scientific understanding and, in turn, societal implications. Such a finer-grained approach is relevant to studying emotion regulation in the context of emotional labor and outside of the work context. A long-term goal of this approach should create more robust theories that can be applied to improve the use of adaptive emotion regulation strategies. The current findings recommend perspective-taking as a particularly optimal strategy for employees' well-being and performance.

Second, it is important to understand a diverse set of emotional labor strategies that employees use to move emotional labor science forward. Our findings suggest that traditionally-studied emotional labor strategies only tell one part of the story. Having a narrow focus on emotional labor strategies would result in a limited understanding of the consequences of emotional labor and, in turn, suboptimal interventions. Instead, understanding the nature of a broader range of strategies can facilitate the development of more efficient programs for employees' health. 


\section{Reference}

Grandey, A. A., \& Gabriel, A. S. (2015). Emotional labor at a crossroads: Where do we go from here? Annual Review of Organizational Psychology and Organizational Behavior, 2, 323-349. https:// doi.org/10.1146/annurev-orgpsych-032414-111400 



\section{Acknowledgments}

Doing my PhD in the Netherlands, away from family and friends, has been challenging yet rewarding. Here I would like to thank my supervisors, colleagues, friends and family who made this journey rewarding.

First, I would like to thank my supervisors, Ute and Philippe for their invaluable mentorship, high standards of research, expertise, understanding, and responsiveness. I feel very fortunate that I worked with these two excellent researchers and reliable mentors. Ute, I read your articles on emotional labor in my masters. Who would have thought that I could be your protegee? :- I am grateful for your invaluable guidance on asking and addressing important questions on this topic. Philippe, I still remember your extensive feedback on my very first draft. You have always encouraged me to turn abstract ideas into concrete and well-written manuscripts. I have learned much from you about putting big ideas into small words :) Thank you both for helping me grow as a researcher. Second, I need to thank my second supervisor, Fred, for his wise advice and support throughout my PhD process.

The work and social psychology department has been a very friendly and stimulating environment to do research. My heartfelt thanks to all my colleagues (past and present) for their emotional and instrumental support. Astin, my office-mate and friend, many thanks for always offering your time, positive energy, and listening ear when times were tough. Abbas, thank you for walks and long talks about life, politics, and academia.

My dear paranymphs, Marie and Bram. Thank you both for your sincere support, humor, friendship, and many intellectual conversations. Marie, special thanks for the inspiring and welcoming work environment and little chats that colored my working days. Bram, I should thank you for always helping me keep perspective. Without your wisdom I would have never been able to be an ambivist/ambivert. I would further like to thank Rosine, Darta, Vera, Alicia, Khalid, and Nino for creating a positive and friendly spirit in the department.

I cannot thank enough my close friends, Secil, Idil, Cansu, Cisil, Hatice, for always being there when I need them. Your support was invaluable. Tom, thank you very 
much for accompanying me along this journey. Your encouragement, patience, understanding, and jokes have been a source of motivation.

I should thank my former mentors for inspiring me to pursue a research-oriented career in Psychology. Mujde hocam, thanks for being a wonderful role model. Carnot hocam big thanks for your academic guidance and support.

Finally, to my family, canlarim, annecigim, Sevgi, kardesim Melda, kuzenim Hulya, yegenim Nil, halam Ayfer, babannem Ayse ve rahmetli dedem Sukru, size, sevginize ve desteginize ne kadar tesekkur etsem az. Sizi cok seviyorum...

Thank you, Dank je, Tesekkurler :)

Merve. 



\section{Curriculum Vitae}

Merve Alabak was born on September 6, 1991, in Edirne, Turkey. She obtained her Bachelor of Arts in Psychology at Isik University, Istanbul, Turkey, in 2014. She then received her Master's of Arts degree in Psychology with a specialization in Industrial and Organizational Psychology at Bilkent University, Ankara, Turkey, in 2016. In 2017, she moved to Maastricht, where she currently resides. She worked as a PhD student in the Work and Social Psychology department at Maastricht University between May 2017 and August 2021. As of September 2021, Merve is working in the same department as a postdoctoral researcher and teacher. 
